\title{
Recent Changes in Hydroclimatic Patterns over Medium Niger River Basins at the Origin of the 2020 Flood in Niamey (Niger)
}

\author{
Giovanni Massazza ${ }^{1,2} \oplus$, Maurizio Bacci ${ }^{3}{ }^{\oplus}$, Luc Descroix $^{4}$, Mohamed Housseini Ibrahim ${ }^{5}$, Edoardo Fiorillo ${ }^{3}{ }^{\circledR}$, \\ Gaptia Lawan Katiellou ${ }^{6}$, Geremy Panthou ${ }^{7}$ (D), Alessandro Pezzoli ${ }^{1}$, Maurizio Rosso ${ }^{8}$, Elisa Sauzedde ${ }^{7}$,

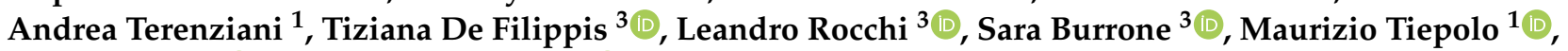 \\ Théo Vischel ${ }^{7}$ and Vieri Tarchiani ${ }^{3, *}$ (D)
}

Citation: Massazza, G.; Bacci, M.; Descroix, L.; Ibrahim, M.H.; Fiorillo, E.; Katiellou, G.L.; Panthou, G.; Pezzoli, A.; Rosso, M.; Sauzedde, E.; et al. Recent Changes in

Hydroclimatic Patterns over Medium Niger River Basins at the Origin of the 2020 Flood in Niamey (Niger). Water 2021, 13, 1659. https:// doi.org/10.3390/w13121659

Academic Editor: Margarida Lopes Rodrigues Liberato

Received: 29 March 2021

Accepted: 9 June 2021

Published: 14 June 2021

Publisher's Note: MDPI stays neutral with regard to jurisdictional claims in published maps and institutional affiliations.

Copyright: (c) 2021 by the authors. Licensee MDPI, Basel, Switzerland. This article is an open access article distributed under the terms and conditions of the Creative Commons Attribution (CC BY) license (https:/ / creativecommons.org/licenses/by/ $4.0 /)$.
1 Dipartimento Interateneo di Scienze, Progetto e Politiche del Territorio (DIST), Politecnico di Torino \& Università di Torino, 10129 Torino, Italy; giovanni.massazza@polito.it (G.M.); alessandro.pezzoli@polito.it (A.P.); andrea.terenziani@polito.it (A.T.); maurizio.tiepolo@polito.it (M.T.)

2 Agenzia Interregionale per Il Fiume Po (AIPo), 10024 Moncalieri, Italy

3 Istituto per la BioEconomia-Consiglio Nazionale delle Ricerche (IBE-CNR), 50019 Sesto Fiorentino, Italy; maurizio.bacci@ibe.cnr.it (M.B.); edoardo.fiorillo@ibe.cnr.it (E.F.); tiziana.defilippis@ibe.cnr.it (T.D.F.); leandro.rocchi@ibe.cnr.it (L.R.); sara.burrone@ibe.cnr.it (S.B.)

4 Unité Mixte de Recherche Patrimoines Locaux, Environnement \& Globalisation (PALOC), Institut de Recherche pour le Développement (IRD), Muséum National d'Histoire Naturelle (MNHN), Sorbonne Université, 75231 Paris, France; luc.descroix@ird.fr

5 Direction de l'Hydrologie (DH), Ministère de l'Hydraulique et de l'Assainissement du Niger, Niamey 8004, Niger; housseiniibrahimmohamed@yahoo.fr

6 Direction de la Météorologie Nationale (DMN), Ministère des Transports du Niger, Niamey 8001, Niger; katielloulaw@gmail.com

7 Institut des Géosciences de l'Environnement, Université Grenoble Alpes, 38058 Grenoble, France; geremy.panthou@univ-grenoble-alpes.fr (G.P.); elisa.sauzedde@univ-grenoble-alpes.fr (E.S.); theo.vischel@univ-grenoble-alpes.fr (T.V.)

8 Dipartimento di Ingegneria dell'Ambiente, del Territorio e delle Infrastrutture (DIATI), Politecnico di Torino, 10129 Torino, Italy; maurizio.rosso@polito.it

* Correspondence: vieri.tarchiani@ibe.cnr.it; Tel.: +39-055-3033734

Abstract: Niamey, the capital of Niger, is particularly prone to floods, since it is on the banks of the Niger River, which in its middle basin has two flood peaks: one in summer (the red flood) and one in winter (the black flood). In 2020, the Niger River in Niamey reached its all-time highest levels following an abundant rainy season. On the other hand, the floods in Niamey have been particularly frequent in the last decade, a symptom of a change in hydroclimatic behaviour already observed since the end of the great droughts of the 1970s and 1980s and which is identified with the name of Sahelian Paradox. This study, starting from the analysis of the 2020 flood and from the update of the rating curve of the Niamey hydrometric station, analyses the rainfall-runoff relationship on the Sahelian basins of the Medium Niger River Basin (MNRB) that are at the origin of the local flood. The comparative analysis of runoffs, annual maximum flows (AMAX) and runoff coefficients with various rainfall indices calculated on gridded datasets allowed to hydroclimatically characterise the last decade as a different period from the wet one before the drought, the dry one and the postdrought one. Compared to the last one, the current period is characterised by a sustained increase in hydrological indicators (AMAX $+27 \%$ ) consistent with the increase in both the accumulation of precipitation $(+11 \%)$ and the number $(+51 \%)$ and magnitude $(+54 \%)$ of extreme events in the MNRB. Furthermore, a greater concentration of rainfall and extremes $(+78 \%)$ in August contributes to reinforcing the red flood's positive anomalies $(+2.23 \mathrm{st} . \mathrm{dev}$ in 2020). The study indicates that under these conditions the frequency of extreme hydrological events in Niamey will tend to increase further also because of the concurrence of drivers such as river-bed silting and levee effects. Consequently, the study concludes with the need for a comprehensive flood-risk assessment on the Niamey city that considers both recent hydroclimatic trends and urbanisation dynamics in flood zones hence defining the most appropriate risk-reduction strategies. 
Keywords: Middle Niger River Basin; Niamey; Sahel; floods; rating curves; runoff coefficients; early warning system; flood risk; levees; hazard thresholds; CHIRPS; TerraClimate

\section{Introduction}

The 2020 hydrological season was exceptionally intense in Central, East and especially in West Africa. The United Nations Office for the Coordination of Humanitarian Affairs reported floods in 18 West and Central Africa countries having affected 2.3 million people [1]. In West Africa, floods occurred mostly during the month of September (Niger, Nigeria, Cameroon, and Burkina Faso), with some events also in August (Niger and Mali), July (Niger and Mali) and June (Ivory Coast, Ghana and Nigeria) [2,3]. In 2020, floods affected several West African capital cities: especially being either «fluvial» (caused by rivers overflowing, such as in the case of Niamey) or "pluvial» (caused by intense rain such as in the case of Dakar) in a rising trend marked by the historical floods of Ouagadougou (1 September 2009) and Dakar (26 August 2012).

The impacts in 2020 were particularly severe, and the number of people affected doubles those of 2019. The most affected countries were Niger and Nigeria with respectively more than 5 and 4 hundred thousand people affected [1]. Floods destroyed houses, infrastructures, goods, crops and fields, besides exacerbating land degradation, erosion and silting. Moreover, floods threat livelihoods of rural communities which in many of the affected regions already struggle with food insecurity. Floods also raise the incidence of water-borne diseases, especially where water stagnates for weeks as is the case in Niamey, Niger capital city, after the flood of early September.

The events of 2020 are not isolated but are part of a broader dynamic that has seen a sharp increase in flood events and damages since the turn of the century. Tarhule [4] first pointed out that extreme flooding was becoming a crucial issue for the development of Sahelian countries. During the last 20 years, many authors reported a growing number of floods and flood-related impacts in West Africa. Nka et al. [5] analysed the flood trends with a regional perspective on 11 catchments and found a significant increase in flood magnitude and frequency in the Sahelian area. Aich et al. [6] confirmed the positive trends of flood magnitude and their relationship with the number of people affected in the Sahelian part of the Niger River Basin. Fiorillo et al. [7] demonstrated a sharp increase of flood events and related damages in Niger, particularly in the Tillabery, Niamey and Dosso regions. Positive flood trends are directly linked with changes in Sahelian rivers' flow, which have been deeply studied by several authors [6,8-11]. Recently, Wilcox et al. [12] analysed the annual maxima of daily discharge (AMAX) of several rivers in West Africa. They confirmed the increasing trends in extreme discharges in the Sahelian reach of the Niger River and demonstrated the significant non-stationarity of extreme flow values for some Sahelian tributaries over the past six decades. Non-stationary methods in trend analysis have also been used by Massazza et al. [13] on the Sirba River, the main tributary of the Middle Niger River Basin (MNRB) to compute the occurrence of flood events in a framework of drastically changing river hydrology.

The increase in the Sahelian rivers' flow rates, in contrast to the rainfall regime during the dramatic droughts of the 1970s and 1980s and till the mid-1990s, was defined as the first Sahelian hydrological paradox [14,15]. The increase of flow rates associated with the so-called 're-greening' of the Sahel [16] after the droughts is referred to the second Sahelian paradox [17]. The first Sahelian paradox is usually explained by changes in Land Use and Land Cover (LULC) due to drought and anthropogenic factors such as population growth, over-cropping and over-grazing [15]. These changes alter the soil surface conditions and the soil hydraulic conductivity [18] resulting in increasing surface and underground runoff [19]. The second paradox is explained by changes in the soil water-holding capacity despite vegetation recovery [11], by a decreasing trend in woody vegetation [20] and by increasing 
drainage network $[19,21]$ among other factors. At the same time, the two paradoxes are also supported by the increase in extreme rainfall events [22].

The MNRB fully responds to the first Sahelian paradox, partially to the second since the right bank of MNRB (North Burkina Faso) shows contrasting vegetation trends while the left one (south-west Niger) does not $[15,17,23]$. According to the first Sahelian paradox, the runoff coefficients of Sahelian tributary basins on the right bank increased significantly during the drought and exponentially with the rainfall recovery after the mid-1990s [10,15]. The long-term increase in surface runoff production, in Western Niger, coincides with a substantial increase of drainage density [19] and endorheism bursting [24]. Both authors relate these phenomena to trends in land clearing and generally LULC changes. Moreover, higher runoff causes an increase in sediment transportation and finally accumulation of sediments in alluvial fans in the Niger River bed [25]. Some authors attribute to Niger river bed silting the basic cause of the increase in flooding frequency in Niamey [24,25]. Moreover, silting and erosion can affect the accuracy of data. Hydrological data for MNRB tributaries is provided by a limited number of hydrological stations, placed near the confluence with the Niger River. Data series are available since the 1950s but are often incomplete. The main source of uncertainty for discharge depends on the accuracy of the rating curves. Indeed, their updating should be frequent since the natural sections are subject to morphological changes because of erosion and silting up at gauge sections or downstream boundaries [26]. In the lack of discharge field observations and rating curve update, the flow series can bring significant over or underestimates.

Nevertheless, independently of the discharge, the Niger River is reaching increasingly higher levels, causing recurrent floods of built and crop areas and affecting thousands of people (Figure 1). Riverine floods are not the only hydrological hazard in Niamey, because flash floods are also recurrent mainly because of poor drainage systems and lack of maintenance. The strong current and projected demographic growth in Niger and the urbanisation process of Niamey neighbourhoods are likely to increase the exposure to floods, both for formal and informal settlements in flood-prone areas [27]. Most of these areas are particularly vulnerable because of the high poverty levels, aggravating flood risk and its associated adverse impacts. The urbanisation of rural population following the droughts of the 1970s and 1980s generated enormous housing difficulties and public authorities gave newcomers the freedom to settle even in flood-risk zones [28] unaware of the risk or forced to accept it [29]. 


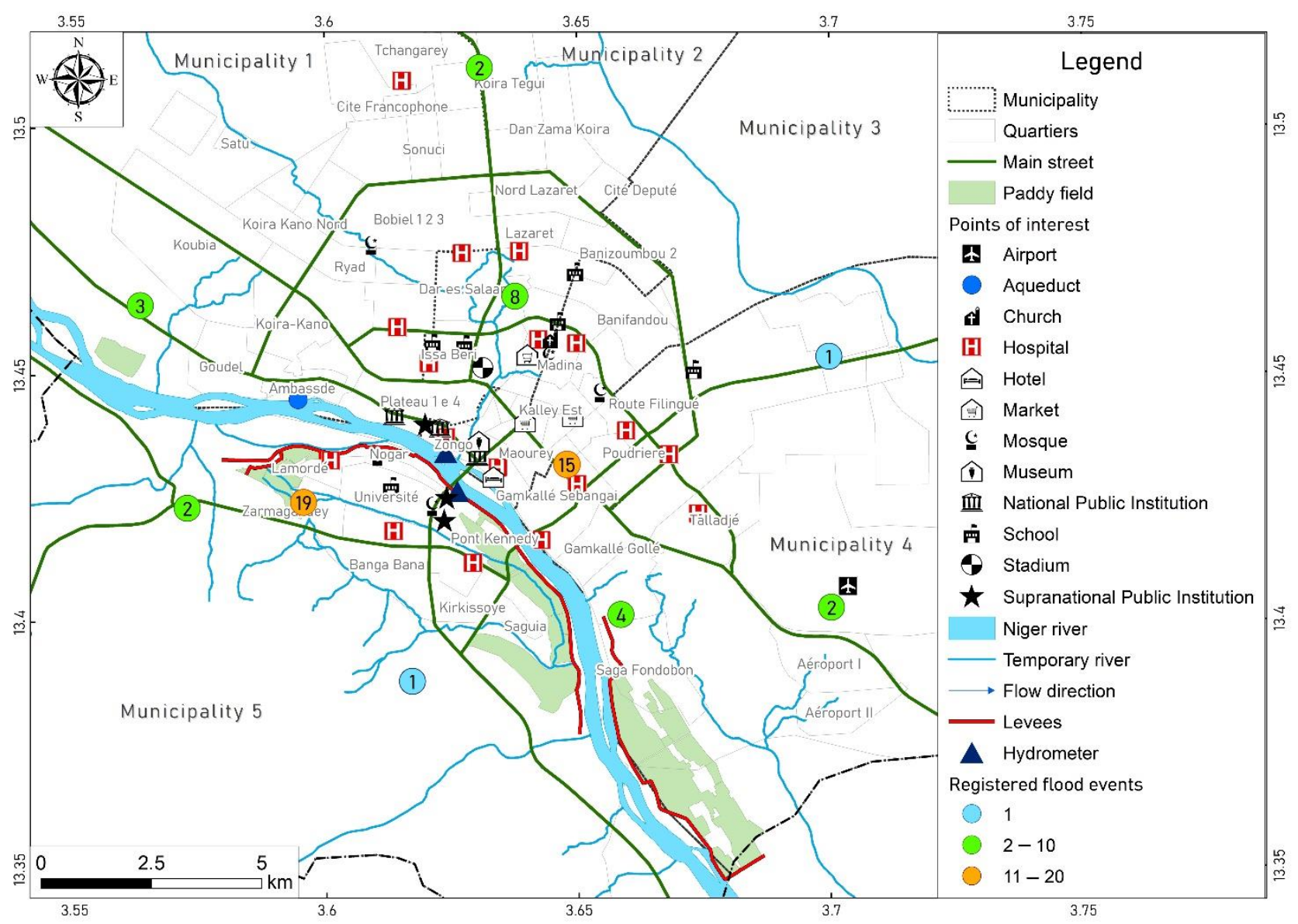

Figure 1. Map of the Niamey city with fluvial and pluvial flood events registered between 1998 and 2019 (Source BDINABase de Données sur les Inondations au Niger ANADIA [30]).

In response to the flood risk, Niamey has been protected with the construction of flood containment embankments ever since the last century. During the last ten years other levees have been built, consolidated or raised. Despite the effort, the Niamey protection system was overwhelmed by the river levels in 2012, 2019 and 2020, demonstrating that the statistical analysis used for hydraulic infrastructure design needs to be updated [31] and the overall flood protection strategy needs to be rethought. Therefore, accurate frequency analysis is required to ensure that flood protection systems can prevent damages even under unprecedented hydrological conditions.

The general objective of this study is contributing to the complex understanding of recent hydrological evolution processes in the MNRB and their relation to Niamey floods. The specific objective of this study is to characterise and contextualise the 2020 flood event in the long and short-range hydroclimatic changes to consequently update the flood hazard assessment for risk prevention and mitigation.

Our hypothesis is that recent (2011-2020) increase of hydrological extremes, beside the well-documented causal relation on the long term with rising human pressure and LULC changes, is strictly related to climate variability. This converging behaviour of long-term drivers and climate features brought to unprecedent hydrological extremes, augmented frequency and impacts of floods.

For this purpose, we updated the Niamey rating curve (last update 2008) and consequently the discharge data series and the discharge frequency analysis, we calculated hydrological and rainfall indices on Sahelian basins and analysed their relation. Moreover, we computed and analysed the runoff coefficients for the Sahelian watersheds and analysed the exceptional 'red floods' that occurred in Niamey during recent years in relation to climatic indices and other concurrent factors such as silting-up and levees effects. 
The study is organised in five sections. The first is this introduction, the second part presents the study area, materials and methods. The third introduces the main results that are discussed in the fourth section. The conclusions are summarised in the fifth section.

\section{Materials and Methods}

To simplify the reading, the acronyms adopted in the research are listed in Table 1.

Table 1. The glossary of acronyms used in the text (acronyms of climatic indices are exposed in Table 3).

\begin{tabular}{cc}
\hline Acronyms & Full Names \\
\hline ADCP & Acoustic Doppler Current Profiler \\
AMAX & Annual Maximum of daily discharge \\
AMIN & Annual Minimum of daily discharge \\
CHIRPS & Climate Hazards Group Infrared Precipitation with Station data \\
DTM & Digital Terrain Model \\
FDC & Flow Duration Curves \\
GEV & Generalised Extreme Value \\
JAS & July-August-September \\
LULC & Land Use and Land Cover \\
MNRB & Medium Niger River Basin \\
NDFI & Normalised Difference Flooding Index \\
NID & Niger Inner Delta \\
NS & Non-Stationary \\
RC & Runoff Coefficient \\
RP & Return Period \\
TC & TerraClimate \\
\hline
\end{tabular}

\subsection{Study Area}

The climate of the MNRB is determined by the West African Monsoon. Rainfall occurs with the seasonal migration of the Intertropical Convergence Zone from the Gulf of Guinea in spring to the Sahara during summer (June-September). The mean annual rainfall amount decreases from south to north, ranging from over $500 \mathrm{~mm}$ near Niamey $\left(\approx 13.5^{\circ} \mathrm{N}\right)$ to less than $250 \mathrm{~mm}$ over the lower Saharan desert limit $\left(>16^{\circ} \mathrm{N}\right)$. The vegetation is characterised by dry savannah and sparse bush scattered by fields of rainfed cereals. Agricultural pressure is higher in the southern part, while deforestation of bushes strongly increases approaching settlements and cities [32].

Niger is the largest river in West Africa, with a theoretical water basin of 2,170,500 km and an active drainage area estimated at around $1,400,000 \mathrm{~km}^{2}$ [33]. The Niger source is in the Fouta Djallon highlands in Guinea from where the river rises to the north until it expands into the Niger Inner Delta (NID) in Mali and then converges to the south crossing Niger, Benin and Nigeria until it reaches the Gulf of Guinea.

The present study focuses on the MNRB drainage area responsible for the Sahelian floods of the Niger River comprised between the confluence Gorouol-Niger river upstream and Niamey in Niger downstream (Figure 2). The effective drainage area is estimated at approximately $125,000 \mathrm{~km}^{2}$ [10]. The right bank of the Ansongo-Niamey reach comprises three major sub-basins: (1) Gorouol, the northern and larger one, spreads across Mali, Burkina Faso and Niger, (2) Dargol, shared between Niger and Burkina Faso, abundantly monitored in the AMMA catch experience [34] and (3) Sirba, the southern one shared between Burkina Faso and Niger, more important in terms of discharge and deeply studied and monitored during the ANADIA 2.0 Project [35]. All three rivers have an intermittent behaviour characterised by discharges only during the rainy season that is observed by a stream gauge close to their confluence with the Niger river (Figure 2).

The Niger River left bank is characterised by smaller catchments largely endorheic with limited contribution to Niger flow. However, since the turning of the century, endorheism bursting has been observed in the small basins on the left bank $[8,19,24]$. 


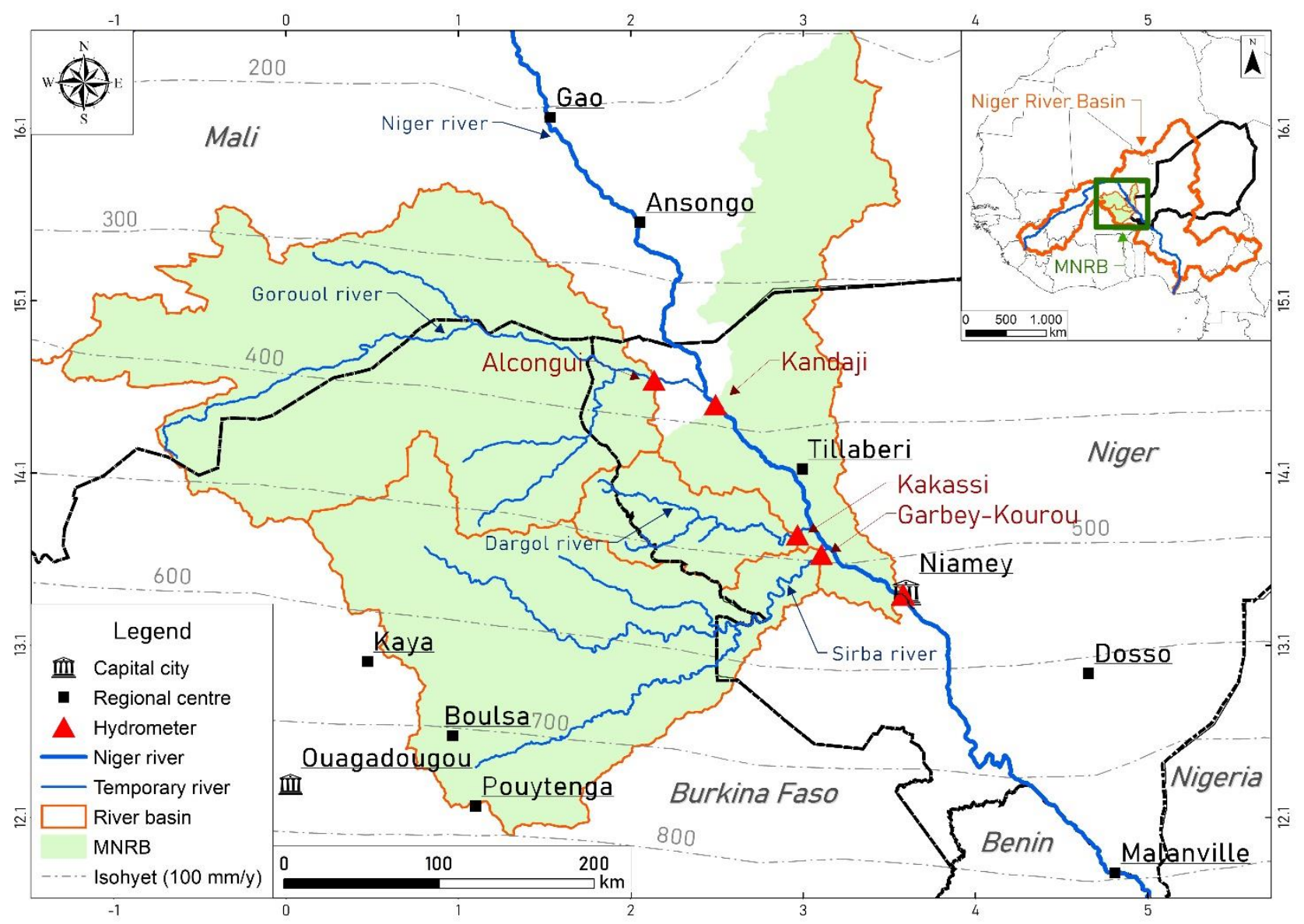

Figure 2. Map of Middle Niger River Basin (MNRB).

\subsection{Hydrology and Floods}

The Niger river at its middle basin experiences two annual peaks:

- The Sahelian flood - called red flood-occurs during the rainy season, between August and September deriving mainly from the inflows of the right bank tributaries upstream of Niamey (Gorouol, Dargol and Sirba);

- The Guinean flood—called black flood-occurs later in the season, between November and February, and is generated by rains occurring in the upper basin watersheds located upstream of the NID in Guinea and Mali. The time lag is due to the propagation time along the river course and to the reservoir effect of the NID.

The black flood had a greater magnitude than the red flood historically, but since 1984 the red peak began to surpass the black one [8] and during the last decade an inversion of the magnitude has been observed with the levels of the red peak regularly exceeding those of the black one. The mean annual hydrographs in Niamey strongly reflect the humid reference period until the 1960s, the dry period in 1970s and 1980s and the last three decades in which the early start and the increase of red peak are clearly visible [15].

Niamey, the capital of Niger, is a large city crossed by the Niger River. The left bank, which houses most of the town, is a plateau overlooking the river at an average altitude of $220 \mathrm{~m}$. The right bank is a floodplain with an average altitude of $185 \mathrm{~m}$. The river thalweg is around $175 \mathrm{~m}$. Niamey has experienced rapid demographic and spatial growth over the past forty years. The population which was of only 33,816 inhabitants in 1960 is estimated at 1,802,910 in 2018, reflecting the increase of surface from 2347 ha in 1972 to 25,500 in 2018. If the left bank is not prone to flooding in general terms, the right bank, urbanised since the 1970s, is located on alluvial deposits and is therefore more vulnerable. Municipality 5 on the right bank was partly built in a river bed's backwater, which periodically reactivates after 
floods. During recent years, the urbanisation was particularly evident in the flood-prone areas of Saguia neighbourhood, on the right bank. Built flood zones do not only concern the so-called traditional or informal neighbourhoods. In fact, the Lamordé district is home to Abdou Moumouni University, two hospitals and other strategic infrastructures. In recent years, the Lamordé-Zarmagandey-Karadjé-Saguia continuum sectors are regularly flooded, if not because of the overflow of the river for the stagnation of rainwater [36]. On the left bank, nevertheless, the upstream district of Goudel and the downstream area of Saga lying on alluvial deposits are also particularly prone to floods.

The flood warning system adopted in Niamey is based on the four-colour classification of risk scenarios associated with critical hydraulic levels and potential impacts. The fourcolour coded classes currently used respond to the international standards (International Organisation for Standardisation-ISO 22324:2015) [37]. Thresholds are based on the river water level $(\mathrm{H})$ at the hydrometric station as follows: Yellow: $\mathrm{H}=530 \mathrm{~cm}$; Orange: $\mathrm{H}=580 \mathrm{~cm}$; Red: $\mathrm{H}=620 \mathrm{~cm}$. These hazard thresholds were defined by a multidisciplinary team composed of national and regional authorities (Ministry of Hydraulic, Ministry of Agriculture, Directorate of Meteorology, Civil Protection, Agrhymet Regional Center and Niger Basin Authority) in the early 2000s to prevent flood damages after the first flood event in 1998 [13].

\subsection{Hydrological Data and Analysis \\ 2.3.1. Hydrological Data Series}

The hydrological analysis conducted in this study adopts the entire discharge series observed in the main hydrometric stations of MNRB since the beginning of the observations. Depth and flow data are extracted from the database of the Niger Directorate for Hydrology (DH) and are updated to 31st December 2020. The majority (3/5) of the stations used here were installed between 1956 and 1961, only Niamey was installed before (1929) and only Kandaji after (1975). Hydrological series are limited since the gaps existing in the manual observations reduce the completeness (the ratio between the number of complete years and the total number of years) from $83 \%$ (Alcongui) to $94 \%$ (Niamey). It is remarkable, however, that the 1941-2020 observations in the gauge station of Niamey are $100 \%$ complete (Table 2). The watershed delineation was conducted in GIS environment using a Digital Terrain Model (DTM) with a $90 \mathrm{~m}$ resolution [38]. Results reflect the hydrological basins defined by Global Runoff Data Centre [39] and HYPE model [40]. The area of Goroul basin is considerably larger compared to the areas used by other studies on MNRB for the Gorouol basin $\left(44,900 \mathrm{~km}^{2}\right)$ since the northern area of the basin, which could not be completely referred to as having an endorheic behaviour, was also considered [10].

Table 2. The main hydrometers used for flow monitoring on the MNRB. The basin area is computed at the hydrometric gauging station.

\begin{tabular}{cccccccc}
\hline Hydrometer & $\begin{array}{c}\text { Rating } \\
\text { Curve }\end{array}$ & River & Country & Basin $\mathbf{( k m}^{\mathbf{2})}$ & $\begin{array}{c}\text { Installation } \\
\text { Date }\end{array}$ & $\begin{array}{c}\text { Complete } \\
\text { Years }\end{array}$ & Completeness \\
\hline Niamey & 2008 & Niger & Niger & 700,000 & 1929 & 86 & $94 \%$ \\
Kandaji & 1979 & Niger & Niger & 628,996 & 1975 & 41 & $89 \%$ \\
Alcongui & 1998 & Gorouol & Niger & 52,933 & 1961 & 50 & $83 \%$ \\
Kakassi & 2000 & Dargol & Niger & 7152 & 1957 & 59 & $92 \%$ \\
Garbey Kourou & 2004 & Sirba & Niger & 39,095 & 1956 & 56 & $86 \%$ \\
\hline
\end{tabular}

\subsubsection{Rating Curves}

It is noticeable that rating curves adopted to convert observed depth in flow data are dated for all hydrometric stations. Regarding the Sirba River, Tamagnone et al. [26] updated the rating curve demonstrating that not-at-date rating curves strongly affect the flow data quality. Therefore, several flow-depth measurements were conducted in Niamey between 2008 and 2020 with Acoustic Doppler Current Profiler (ADCP) tools for 
river section monitoring and rating curve update (Figure 3). Fifteen observations were conducted between 2008 and 2014, 6 in 2015, 2 in 2016, 2 in 2017, 3 in 2018, 5 in 2019 and 6 in 2020. Figure 3 shows the flow velocity distribution measured on the Niger River a few hours after the maximum peak registered in Niamey on the 8th of September 2020.

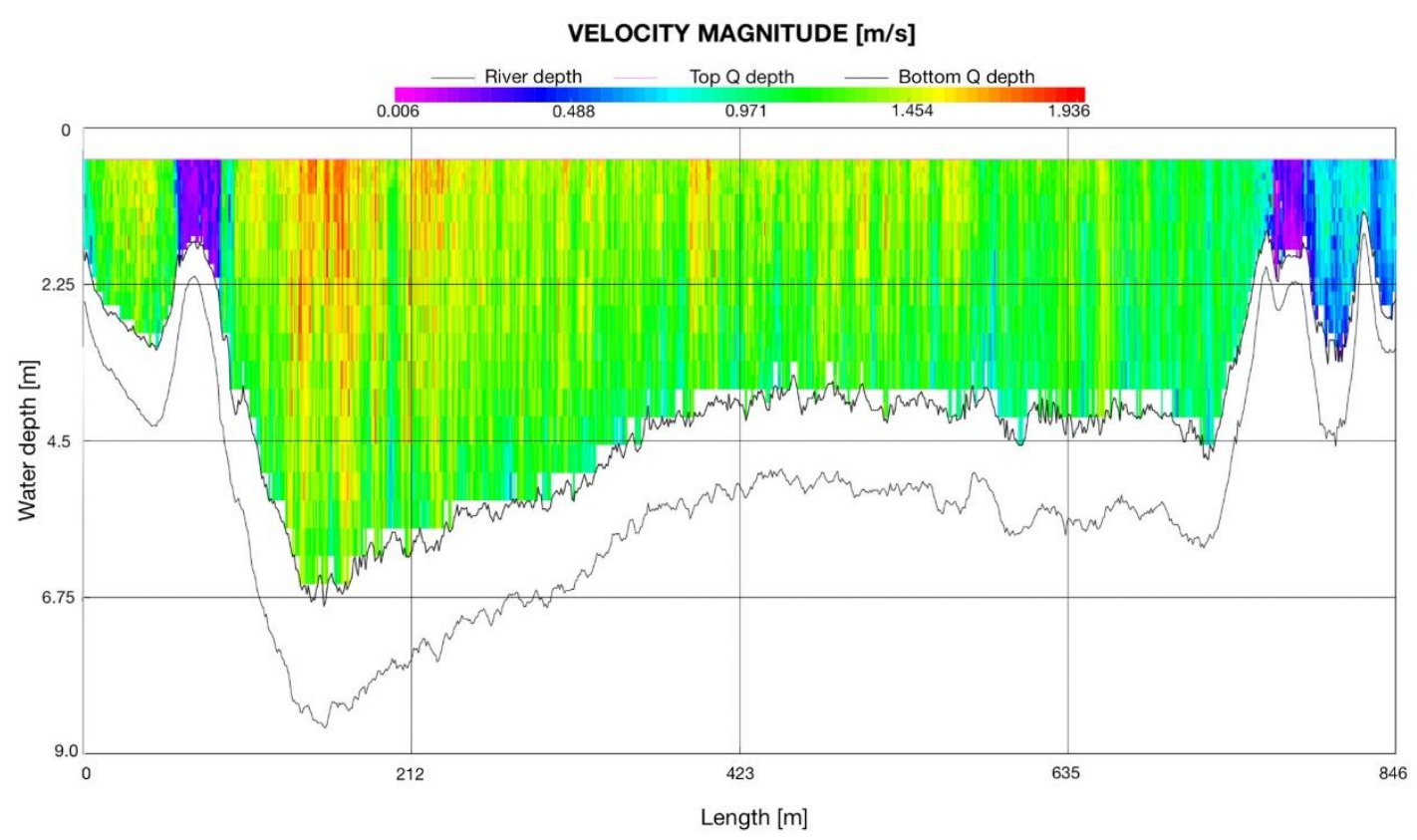

Figure 3. Acoustic Doppler Current Profiler (ADCP) observation conducted in the Niger River in Niamey (Soumana section) on 8 September 2020 with a flow depth of $698 \mathrm{~cm}\left(2850 \mathrm{~m}^{3} / \mathrm{s}\right)$.

The Niamey rating curve was updated using a power-law function with two parameters defined according to a bi-logarithmic interpretation [26,41].

$$
Q=a \times(h-h o)^{b}
$$

where $a$ is the coefficient and $b$ the exponent that define the shape of the curve; $h$ is the stage height $(\mathrm{m})$; and $Q$ is the discharge $\left(\mathrm{m}^{3} / \mathrm{s}\right)$.

\subsubsection{Discharge Frequency Analysis}

Statistical parameters adopted to relate flow thresholds with the probability of occurrence of medium and extreme discharges are: (i) flow duration curves (FDC), the number of days per year of expected flow and (ii) return period (RP), the annual probability of exceedance. RPs are computed separately for the red and black floods' AMAX because the two phenomena: (1) are independently generated by two different basins, (2) undergo two different trends (increase of red AMAX and decrease of black AMAX). The return period computation evaluates four probability density functions such as log-normal, exponential, Gumbel and generalised extreme value (GEV) distributions applied to the AMAX [42,43]. The distributional suitability and the best fit with the dataset were identified using Andersson Darling and Pearson tests [44]. AMAX series, however, show a non-homogeneous trend with increasing probability of high flow in the red flood and decreasing probability of high flow in the black floods. Therefore, a non-stationary (NS) return period analysis was conducted. Non-stationary GEV distribution with temporally varying parameters (NS-GEV) is separately applied on red and black floods. The method is similar to that implemented in Wilcox et al. [12] to which the reader can refer for more details on the mathematical formalism. In short, it consists in making the GEV location parameter vary in time using a linear temporal function whose parameters are adjusted by maximizing the model likelihood. The fitting process also ensures the statistical significance of the 
identified trends. It should be noted that other combinations that allow varying scale and shape GEV parameters have been tested but did not provide better distribution fitting results. The originality of the results presented here lies in the fact that (i) they provide an update to 2020 of the red flood analyses carried out by Wilcox et al. [12] which stopped in 2016 and that (ii) the NS-GEV process is applied separately for the first time on the black and red flood data.

There is indeed a non-negligible contribution of the base flow from Guinean origin on the AMAX even in July-August-September (JAS) period. The red floods were thus dissociated between local streamflow from Sahelian tributaries and Guinean base flow using a method similar to that described in Cassé et al. 2016 [21]. The NS-GEV model was then applied to the AMAX of these Sahelian tributary flows. The final return level estimate was made by adding to the NS-GEV-based discharges an average base flow. Using a unique average baseflow value was possible here because base flow does not show any temporal trend or correlation with the annual maximum of the right bank tributaries. The average base-flow has been adjusted to maximise the correlation between the maximum flood signal over the JAS period at Niamey station and the sum of the AMAX of the Sahelian tributaries' flows and the base flow.

\subsection{Rainfall Data and Analysis}

Rainfall analysis was conducted at two different levels. The first one is the daily time step allowing the calculation of the extreme rainfall indexes. The second one is the yearly time step on the longest time series available over the MNRB enabling the calculation of the runoff coefficients (RC).

\subsubsection{Rainfall Data Sets}

For extreme rainfall indexes calculation, CHIRPS (Climate Hazards Group Infrared Precipitation with Station data) v.2 was selected as the most appropriate high resolution and freely available gridded rainfall dataset in West Africa for hydrological applications [45-47]. CHIRPS dataset covers the period from 1981 to present with a fine spatial resolution of $0.05^{\circ}$ and daily timestep [48]. It can be freely accessed at http:/ / chg.geog.ucsb.edu/data/chirps/ (accessed on 4 February 2021) for the period 1981-2020.

For the RC analysis the monthly temporal scale of rainfall dataset was selected because recent evaluations of gridded rainfall products in West Africa revealed that their agreement with gauge observations is significantly better at monthly rather than at daily or decadal scales [45,49]. TerraClimate (TC) reanalysis of rainfall monthly data at $\sim 4 \mathrm{~km}$ (1/24th degree) spatial resolution were used [50]. Even if CHIRPS v.2 monthly precipitation has higher accuracy compared to TC reanalysis [51], TC has been selected because of its longer data series 1958-2019. TC dataset is freely available at http:/ / www.climatologylab. org/terraclimate.html (accessed on 4 February 2021). Total rainfall for 2020, not yet available in the TC dataset, was reconstructed through linear regression between TC and CHIRPS v2 monthly rainfall on the common series 1981-2018. Indeed, the 2019 TC dataset showed abnormally low values for the annual precipitation compared to CHIRPS, correctly characterising it as a humid year. Therefore, for the sake of the assessment we also reconstructed 2019.

Statistics were calculated per each defined sub-basin (Figure 2):

- The Gorouol basin at Alcongui;

- The Sirba basin at Garbey Kourou;

- The Dargol basin at Kakassi;

- The basin of Small koris (tributaries) on the left bank;

- The whole MNRB (the sum of the previous four basins).

TC dataset was used for calculating the annual precipitation depth for each grid point and then averaging the values of all the grid points inside a given basin contour. Using the same procedure, CHIRPS monthly precipitation was extracted over the 1981-2020 period enabling the reconstruction of the 2019 and 2020 of TC values. For the CHIRPS daily 
dataset, the procedure of statistics extraction is similar, but considering the typical rainfall distribution over West Africa we selected only the months from April to October.

\subsubsection{Rainfall Indexes}

To compute the rainfall indexes (Table 3), the daily precipitation was temporally aggregated to construct monthly and yearly statistics using a suite of command-line operators from NetCDF Command Operators and Climate Data Operators. Indices based on percentile thresholds were computed using 1981-2020 as the baseline period. Then, the basin extreme rainfall index value was computed averaging each grid point value of the sub-basin. Rainfall indices (1981-2020) include some of those proposed by the Precipitation Indices Expert Team on Climate Change and Detection Indices [52] integrated with some other user-defined indices.

Table 3. Extreme rainfall indices used in this study.

\begin{tabular}{|c|c|c|c|}
\hline ID (Zhang ID) & Indicator Name & Indicator Definitions & Units \\
\hline RSUM (PRCPTOT) & Annual total wet-day precipitation & Annual total precipitation from days $\geq 1 \mathrm{~mm}$ & $\mathrm{~mm}$ \\
\hline RR1 & Annual count of wet days & Number of days with precipitation $\geq 1 \mathrm{~mm}$ & days \\
\hline SDII & Simple daily intensity index & $\begin{array}{l}\text { The ratio of annual total precipitation to the } \\
\text { number of wet days }(\geq 1 \mathrm{~mm})\end{array}$ & $\mathrm{mm} /$ day \\
\hline N_days_95P & Annual count of very wet days & $\begin{array}{l}\text { Annual number of days with precipitation } \\
>95 \text { th percentile }\end{array}$ & day \\
\hline N_days_95C July & July count of very wet days & $\begin{array}{l}\text { July number of days with precipitation } \\
\qquad>95 \text { th percentile }\end{array}$ & day \\
\hline N_days_95C August & August count of very wet days & $\begin{array}{l}\text { August number of days with precipitation } \\
\qquad>95 \text { th percentile }\end{array}$ & day \\
\hline N_days_95C Sept. & September count of very wet days & $\begin{array}{l}\text { September number of days with precipitation } \\
\qquad>95 \text { th percentile }\end{array}$ & day \\
\hline Rainfall 95P (R95p) & Very wet days & $\begin{array}{l}\text { Annual total precipitation from days } \\
\quad>95 \text { th percentile }\end{array}$ & $\mathrm{mm}$ \\
\hline Contribution 95P & Contribution very wet days & $\begin{array}{l}\text { The ratio of Annual total precipitation from } \\
\text { days }>95 \text { th percentile to the number of days } \\
\text { with precipitation }>95 \text { th percentile }\end{array}$ & $\%$ \\
\hline RMAX1 (RX1day) & Max 1-day precipitation amount & Annual maximum 1-day precipitation & $\mathrm{mm}$ \\
\hline RMAX5 (RX5day) & Max 5-day precipitation amount & $\begin{array}{l}\text { Annual maximum consecutive } \\
\text { 5-day precipitation }\end{array}$ & $\mathrm{mm}$ \\
\hline ARI & Standardised Annual rainfall index & $\begin{array}{l}\qquad A R I=\left(R_{\mathrm{y} 1}-R_{\mathrm{av}}\right) / \sigma \mathrm{s} \\
\text { where Ry1 is the annual rainfall, } \mathrm{R}_{\mathrm{av}} \text { is the } \\
\text { mean annual rainfall on the data series and os } \\
\text { is the standard deviation in the reference } \\
\text { period [53]. }\end{array}$ & Dimension-less \\
\hline
\end{tabular}

\subsection{Runoff Coefficients}

RC was computed in each basin for each year covered by rainfall and flow data. Flow annual series not fully complete to ensure data reliability were filled according to the constant trend and a behaviour observed in similar years [54]. The $R C$ values were computed as the ratio between annual runoff volume $(V)$ observed in the gauging stations and the annual rainfall volume over the basin.

$$
R C=V /\left(R_{S U M} \times A\right)
$$

where $V$ is the annual runoff volume in $\mathrm{m}^{3}, R_{S U M}$ is the annual mean rainfall over the basin in $\mathrm{m}$ and $A$ the basin area in $\mathrm{m}^{2}$. 


\subsection{Data Segmentation and Statistics}

Hydrological and climatic data series have been segmented with the Hubert method [55] using the Khronostat ${ }^{\circledR}$ software as described by Descroix et al. [10]. Considering the heterogeneity of the data series, the reduced length of the rainfall indexes series and the discontinuity of hydrological data for some basins, results have been retained only for annual cumulated precipitation over MNRB and AMAX at the Niamey station. For the other data series, a segmentation in fixed periods according to the hydroclimatic behaviour of MNRB defined by the literature has been used:

I. Beginning of the data series-1970: pre-drought humid reference period.

II. 1971-1990: drought period with a decrease in both rainfall and river flows.

III. 1991-2010: recovery after the drought with an increase in rainfall and a strong increase in river flows [15].

IV. 2011-2020: the current period according to the hypothesis that it is significantly different from the previous.

Three statistical tests were used to assess the differences among different periods. In the case of normally distributed variables, the t-student test (t-test) was used to estimate the significance of difference in means between two consecutive periods. In case of non-normal distribution, the Wilcoxon-Mann-Whitney test (U-test) was used to verify whether observations in one period are significantly larger (or smaller) than observations in the other. Then the quantile regression was used to test for difference in median between two consecutive periods and to compute the effect size [56]. We tested variables' normal distribution in the different periods through the Shapiro-Wilk test and the Skewness/Kurtosis test, results are available under request.

\subsection{Topography of Flood-Prone and Flooded Areas Mapping}

The topography of the Niamey flood-prone zones was derived from a high resolution $(0.4 \mathrm{~m})$ digital terrain model (DTM) derived by an unmanned aerial vehicle flight realised by Drone Africa Service [57] in April 2018. This DTM was vertically aligned with a real-time kinematic GPS survey realised in September 2018 for precisely determining the hydrometric zero of the staff gauges of Niamey. All the levels were referred to a local reference system where the elevation is based on the altitude on the hydrometric zero of the gauging staffs aligned with the hydraulic slope of the water surface.

$$
H_{L}=H_{R}-H_{Z}+(j \times L)
$$

where $H_{L}$ is the local elevation in $\mathrm{m}, H_{R}$ is the upper sea level elevation (m.a.s.l.), $H_{Z}=174.85$ is the elevation of the hydrometric zero (m.a.s.l.), $j$ is the hydraulic slope (-) and $L(\mathrm{~m})$ is the distance from the hydrometer (negative downstream and positive upstream).

Flooded area maps were derived from cloud free high resolution $(10 \mathrm{~m})$ Sentinel 2 imagery acquired in August (16th) and September (5th, 10th, 15th, 25th and 30th) 2020. Flooded areas were identified using the NDFI (Normalised Difference Flooding Index) index [58]. Built areas in flooded zones were derived from a shapefile of Niamey built plots [36].

\section{Results}

The results presented hereafter aim to contextualise the flood event of 2020 within the hydrological and climatic changes started in the MNRB since the droughts of the 1970s and 1980s and the paroxysmal bursting during the last decade.

The underlying drivers of hydrological changes on the long term in the MNRB have been largely studied and discussed. The updated review of Descroix et al. [15] clearly explains that the general trend is the result of multiple interconnected changes where climate is just one of many (population growth, LULC changes, urbanisation, soil degradation, etc.). Nevertheless, short-term changes and annual fluctuations have as main driver the climatic variability whose sudden effects overlap the underlying trend due to all other 
factors. Therefore, starting from observed hydrological effects (recent red floods in Niamey) and acknowledging the comprehension of hydrological long-term processes in the Sahel from the literature, we analyse the short-term variability focusing on the last decade and particularly on its extreme years.

\subsection{Flood Dynamic and Levee Role}

The red flood of 2020 registered the highest water level ever reached at $701 \mathrm{~cm}(8$ September at 7 a.m.) since the installation of the Niamey gauging station in 1929. The flood of paddy fields and suburban neighbourhoods had begun three weeks before, but it was only on September 6th that large built areas in Municipality 5 of Niamey, as well as the districts of Gamkalley and Saga on the left bank, were flooded due to the breach in the Lamordé levee (Figure 4). At that point, the flood wave reached a plateau and a slow decline began (Figure 5). Diachronic NDFI mapping of flooded areas shows that several tens of hectares of built neighbourhoods remained flooded for almost one month even after the river level had declined below the red alert threshold $(620 \mathrm{~cm})$, because levees, obstacles and low areas prevented water from returning to the river bed.

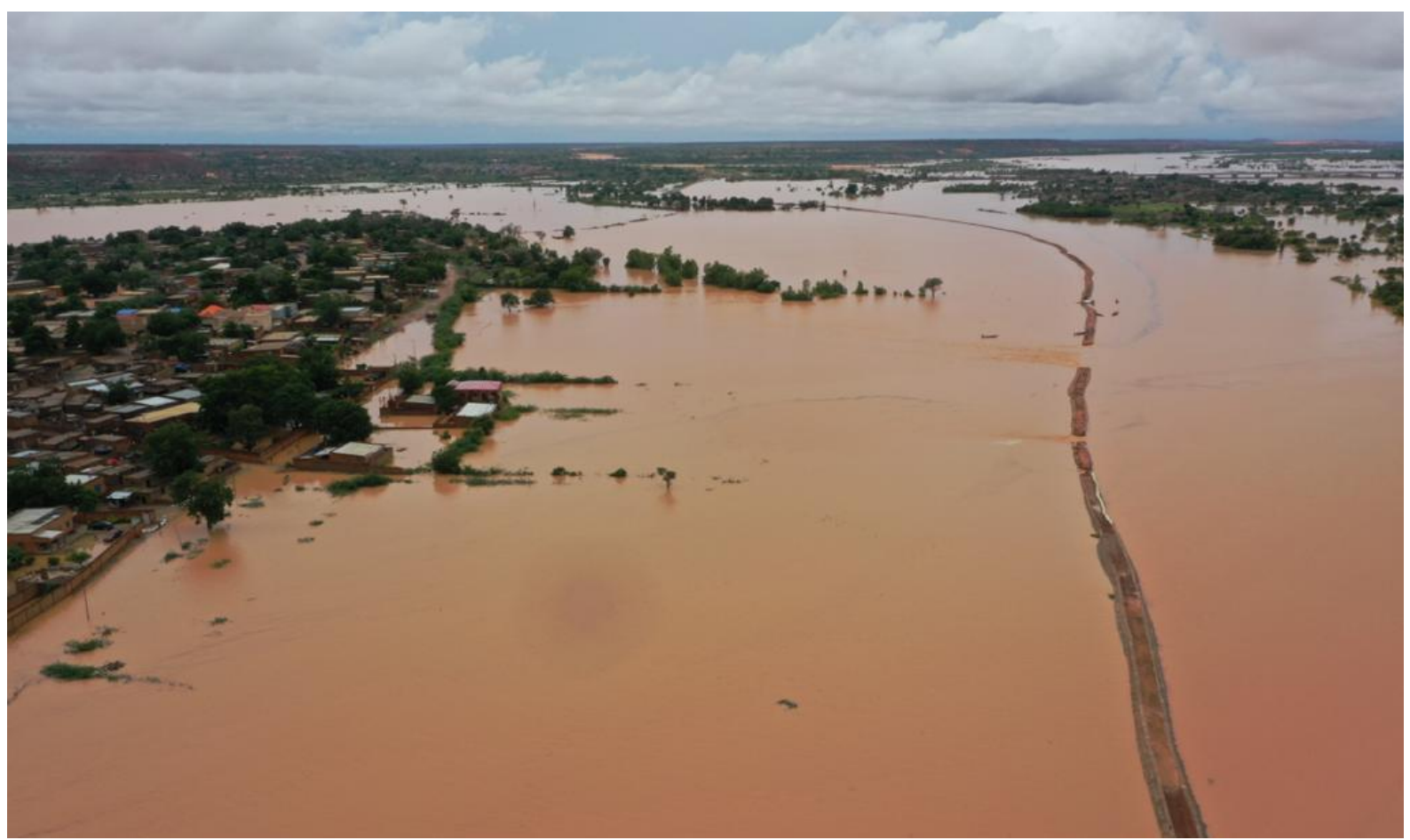

Figure 4. The Niger River in Niamey on 7 September 2020: The Lamordé levee and district on the right bank from the downstream aerial point of view (Author: Direction Générale de la Protection Civile du Niger).

The $21.78 \mathrm{~km}$ flood protection system of the City comprises four sectors:

A. Lamordé $(6.87 \mathrm{~km})$ : right bank upstream Kennedy bridge for residential area protection (Lamordé, Nogar, Zarmagondé, Karadjé and Université districts);

B. Bridges $(1.96 \mathrm{~km})$ : right bank between Kennedy and Chinese bridges for residential area protection (AGRHYMET area);

C. Kirkissoye-Saguia $(4.72 \mathrm{~km})$ : right bank downstream Chinese bridge for residential area (Saguia and Kirkissoie districts) and paddy field protection;

D. Saga $(8.24 \mathrm{~km})$ : left bank downstream the city centre for residential area (Saga and Gamakalé districts) and paddy field protection. 


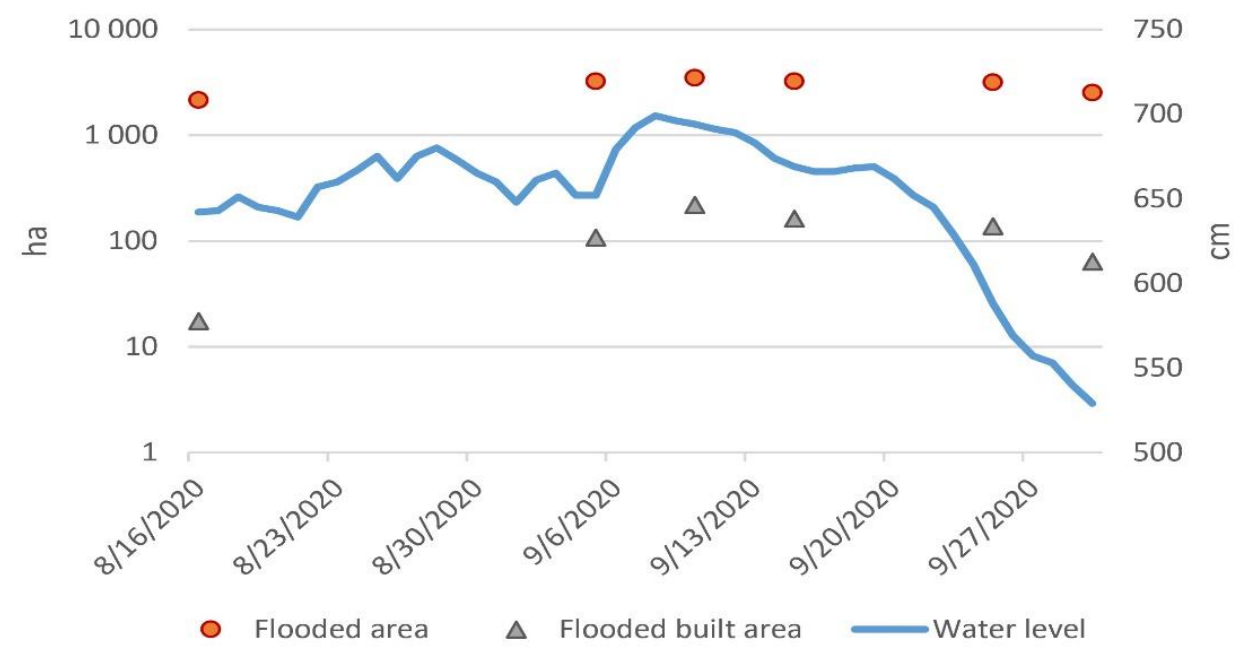

Figure 5. Evolution of flooded areas in Niamey during the 2020 flood (21/8, 26/8, 31/8 and 20/9 images were not usable due to cloud coverage).

Sectors A and D (partially built and partially consolidated after the 2012 flood) are composed of a compacted embankment with a clay core covered with concrete panels and a concrete-laterite pavement (Figure 6). The DTM analysis identifies the levee crest of A sector between 693 (minimum) and $725 \mathrm{~cm}$ (maximum) and Saga ones between 650 and $660 \mathrm{~cm}$. Sectors B and C are composed by a compacted embankment with a clay core that is not covered since they were built before the 2012 flood and reinforced after. Crest of B and $C$ sectors are placed between 601 and $650 \mathrm{~cm}$, but during the 2020 flood event they were raised with laterite material and sandbags (Figure 7A).

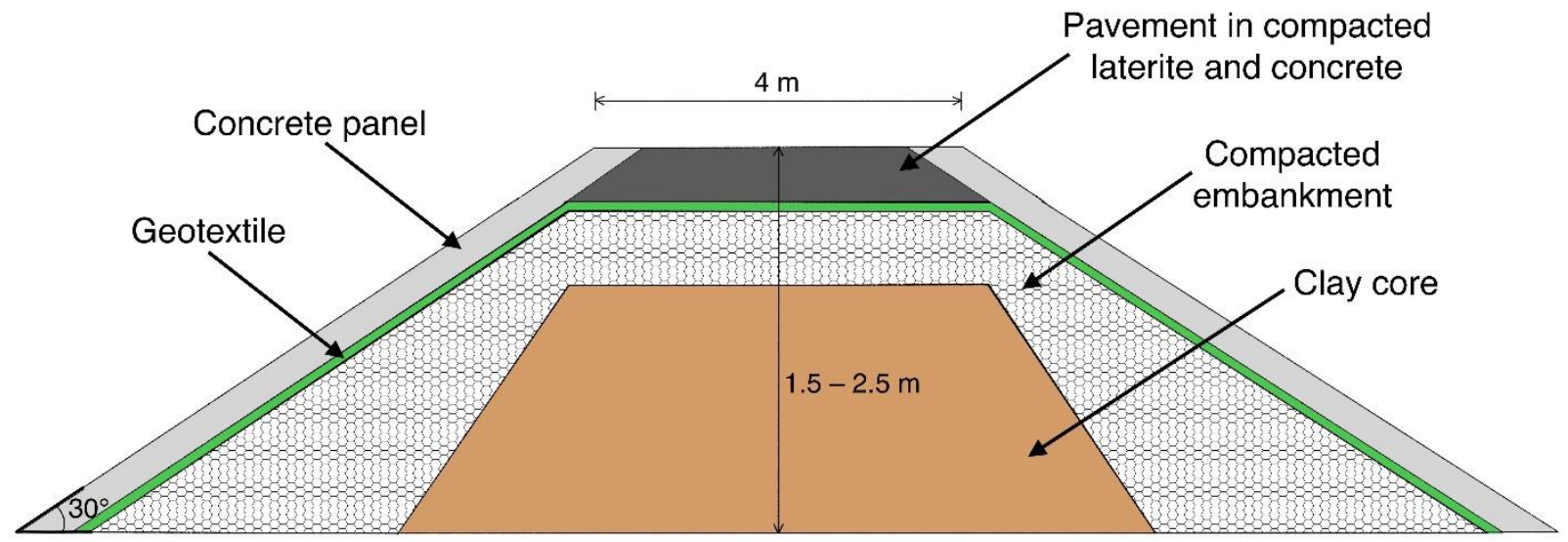

Figure 6. The cross-section of Niamey levees in the Lamordé (sector A) and Saga (sector D).

The 2020 flood surpassed the levees at all the four sectors. The sector B and D were exceeded on August 23 (at a level of $660 \mathrm{~cm}$ ) and breaks occurred in sector A (on September 6th at a level of $679 \mathrm{~cm}$ ) and C. The breaks (Figure 7B) were caused by the panel disconnection caused by the flow velocity and by the seepage flow in the embankments. Particularly ADCP measures identified a flow velocity on the embankments in the range $1.5-2 \mathrm{~m} / \mathrm{s}$. In conclusion, even without breaks, A sector would be exceeded by the flood peaks in the lower sections. Raising the levee, however, allowed to substantially increase the levee crest but not enough to prevent overflow. 

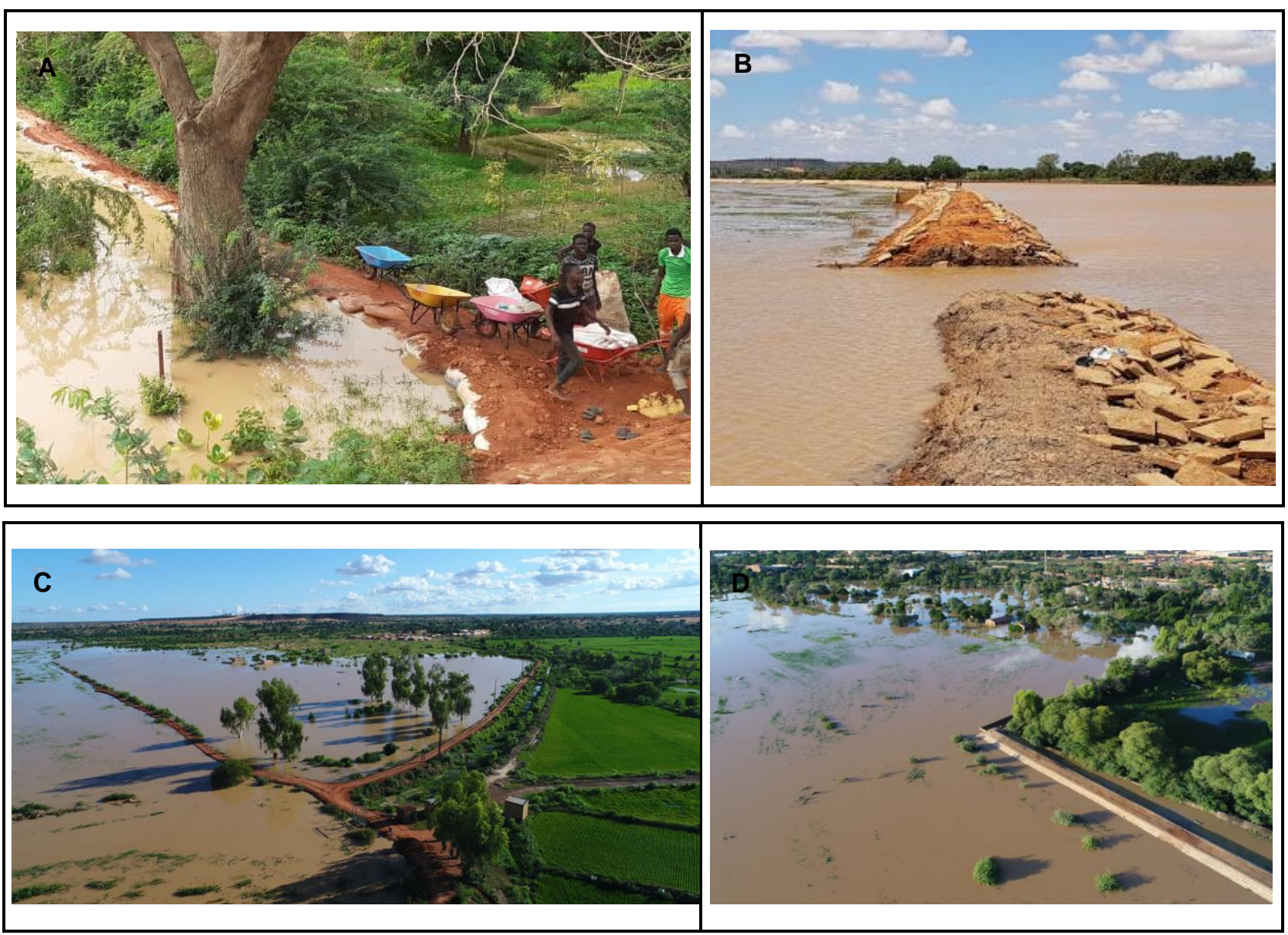

Figure 7. The Niamey levees during the 2019 and 2020 flood events: (A)(top-left) the bridges levee (sector B) raise with sandbags on 18/8/20 ( $\mathrm{h}=651 \mathrm{~cm}),(B)($ top-right) the levee break in Lamordé (Sector A) on 6/9/20 ( $\mathrm{h}=679 \mathrm{~cm}),(\mathrm{C})(\mathrm{bottom}-$ left) aerial view of Kirkissoie levee on 30/8/19 $(\mathrm{h}=619 \mathrm{~cm}),(\mathrm{D})($ bottom-right) aerial view of Saga levee on 30/8/19 $(\mathrm{h}=619 \mathrm{~cm})$.

\subsection{Hydrological and Hydraulic Analysis}

\subsubsection{Rating Curve}

The new rating curve for the Niamey gauging station was computed according to equation \#1, $a$ and $b$ coefficients were computed to maximise the determination coefficient $\left(\mathrm{R}^{2}\right)$ while the zero-flow depth $\left(h_{0}\right)$ was derived from field observations. The depth range was defined in the range between $h_{0}$ until the maximum flow measured in the river at a water height of about $7 \mathrm{~m}$ (Table 4 ).

Table 4. Coefficient and application range of the rating curve equation of Niamey hydrometer.

\begin{tabular}{cccccc}
\hline Validity & $\mathbf{H}(\mathbf{m})$ & $\mathbf{h}_{\mathbf{0}}(\mathbf{m})$ & $\mathbf{a}$ & $\mathbf{b}$ & $\mathbf{R}^{\mathbf{2}}$ \\
\hline 1 June 2016-now & {$[0.9-7]$} & 0.9 & 89.891 & 1.873 & 0.992 \\
\hline
\end{tabular}

The temporal validity of the rating curve was determined following the comparison between the 39 stage-discharge measurements, the 2008 rating curve and the new one. Figure 8 clearly shows that flow measurements until 2013 adequately reflect the 2008 rating curve while starting from 2015 a slight discrepancy was observed. Flow-depth observations since 2016 strongly differ from the old rating curve; therefore, the updated rating curve was established using the 18 ADCP measurements conducted during the 2016-2020 period. The updated rating curve was applied since the start of the 2016 hydrologic year (1 June 
2016) and was therefore called 2016 rating curve even if it was determined by $\mathrm{DH}$ and approved by Niger Basin Authority in December 2020.

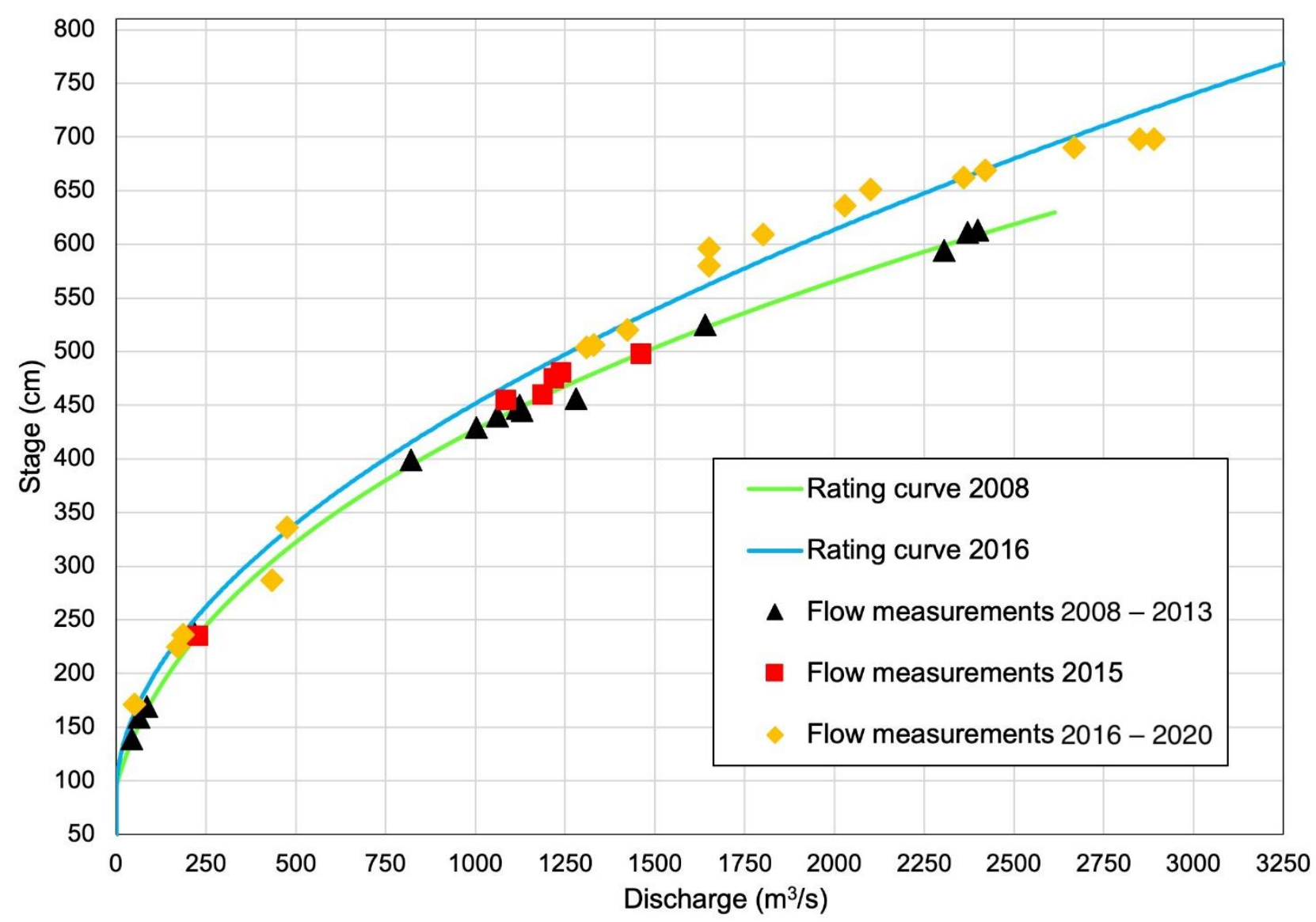

Figure 8. Comparison between the rating curves 2008 (green) and 2016 (blue) and the flow measurements: $2008-2013$ (black triangle), 2015 (red square) and 2016-2020 (orange diamond).

The $\mathrm{R}^{2}$ of the updated rating curve (0.992) demonstrates a good fitness with ADCP observations. Gaps between observations and the curve were mainly observed in the ranges of 580-650 and $690-700 \mathrm{~cm}$. These shifts are causally related to the presence of levees in the cross-section. The minor discharge observed in the range $580-650 \mathrm{~cm}$ is related to the reduced section caused by the presence of the embankments. The supplementary flow observed above $690 \mathrm{~cm}$ is caused by the significant discharge flowing behind the levees over the Niamey floodplain that acts as an enlargement of the river bed after the Larmordé levee break. The discrepancy ranges between $-6.6 \%$ and $-9.2 \%$ in the first range and between $+3.2 \%$ and $+8.5 \%$ above $690 \mathrm{~cm}$; this allows to consider the curve valid for the whole range. However, the changing slope above $700 \mathrm{~cm}$ entailed limiting the application range of the Niamey rating curve at this level in order not to encounter significant underestimations for exceptional levels.

The rating curve update allows for better flow monitoring and to revise maximum and mean values for statistical analysis and discharges associated with the hazard thresholds. This update allowed to recalculate the exceptional red AMAX registered in 2019 (reduced to $-19 \%$ from 2676 to $2162 \mathrm{~m}^{3} / \mathrm{s}$ ) and 2020 (reduced to $-22 \%$ from 3393 to $2653 \mathrm{~m}^{3} / \mathrm{s}$ ).

\subsubsection{Frequency Analysis}

The frequency analysis over the Niamey flow series directly relates the flood hazard thresholds both to updated flow and the annual and interannual occurrence probability in the river. The FDC and return periods of flood hazard thresholds are summarised in Table 5. 
FDC, computed on the last hydrological period (2011-2020), clearly shows that hazard threshold exceedances are expected each year: 80 days/year a flow higher than the greenyellow threshold, 20 days/year a flow in the orange condition and also 2 days/year a flow in the red one. This probability index, even if influenced by the long residence time of the Guinean floods, points out a critical condition. Return period analysis, conducted over the 1929-2020 period, confirms that hazard thresholds were exceeded with high frequency. In particular, the orange-red threshold $(620 \mathrm{~cm})$ is expected to be exceeded with a frequency of 15 and 7 years respectively by the Sahelian and the Guinean floods (Table 5).

Table 5. Flood hazard thresholds (depth and flows) for the Niamey city and related return periods for red and black floods $\left({ }^{* 1}\right.$ Rating curve 2008, ${ }^{* 2}$ Rating curve 2016, ${ }^{* 3} \mathrm{Q}<\mathrm{Q}_{365},{ }^{* 4}$ over the period 2011-2020, ${ }^{* 5} \mathrm{Q}<\mathrm{Q}_{1},{ }^{* 6}$ for year 2020, ${ }^{* 7}$ infinite).

\begin{tabular}{|c|c|c|c|c|c|c|c|c|c|}
\hline \multirow[b]{2}{*}{ Colour } & \multirow{2}{*}{ Importance } & \multirow{2}{*}{$\mathrm{h}_{\text {MAX }}(\mathrm{cm})$} & \multicolumn{2}{|c|}{$\mathrm{Q}_{\mathrm{MAX}}\left(\mathrm{m}^{3} / \mathrm{s}\right)$} & \multirow{2}{*}{$\begin{array}{c}\text { FDC }{ }^{* 4} \text { (Days } \\
\text { in a Year) }\end{array}$} & \multicolumn{2}{|c|}{ Return Period (Years) } & \multicolumn{2}{|c|}{ NS RP (Year) *6 } \\
\hline & & & Old $* 1$ & New $* 2$ & & $\begin{array}{c}\text { Red } \\
\text { Flood }\end{array}$ & $\begin{array}{l}\text { Black } \\
\text { Flood }\end{array}$ & $\begin{array}{l}\text { Red } \\
\text { Flood }\end{array}$ & $\begin{array}{l}\text { Black } \\
\text { Flood }\end{array}$ \\
\hline grey & Low flow & 140 & 47 & 25 & $* 3$ & / & / & / & / \\
\hline green & $\begin{array}{l}\text { Normal } \\
\text { condition }\end{array}$ & 530 & 1700 & 1443 & 80 & 2.7 & 1.2 & 1 & 1 \\
\hline yellow & $\begin{array}{l}\text { Frequent } \\
\text { flood }\end{array}$ & 580 & 2127 & 1766 & 20 & 6.5 & 2 & 1.2 & 10 \\
\hline orange & Severe flood & 620 & 2512 & 2045 & 2 & 15 & 7 & 2 & 28,000 \\
\hline TOP & Top levees & 660 & 2937 & 2344 & $* 5$ & 39 & 34 & 4.2 & $* 7$ \\
\hline red & $\begin{array}{l}\text { Catastrophic } \\
\text { flood }\end{array}$ & 750 & 4055 & 3084 & $* 5$ & 425 & 4700 & 25 & $* 7$ \\
\hline
\end{tabular}

In Table 5, the top levees level was placed at $660 \mathrm{~cm}$, the level overtopped during the 2020 flood event. The RP analysis highlights that this level could potentially be reached with a frequency between 34 (black flood) and 39 (red flood) years.

The introduction of non-stationarity in the frequency analysis leads to a reconsideration of the estimated frequencies of occurrence under the assumption of a stationary flow regime. Inserting a single (red flood) and double (black flood) linear temporal function in the GEV location parameter (Figure A1) significantly improves the fit of the GEV to the AMAX series and substantially changes the estimate of return periods. It is worth noting the difference between stationary and non-stationary RP leading to a revision of the RP of red threshold from 425 years under the stationary hypothesis, to only 25 years under NS one in 2020. On the contrary, for the black flood the RP under non-stationary hypothesis tends to be infinite. Indeed, the black flood discharge for three frequency scenarios of 2, 10 and 100 years shows a downward behaviour since the late 1990s (Figure 9A) while the red flood has a clear upward trend (Figure 9B). This result is coherent with the increasing trend in the discharge of the right bank tributaries since 1985, already observed by several authors and further analysed below.
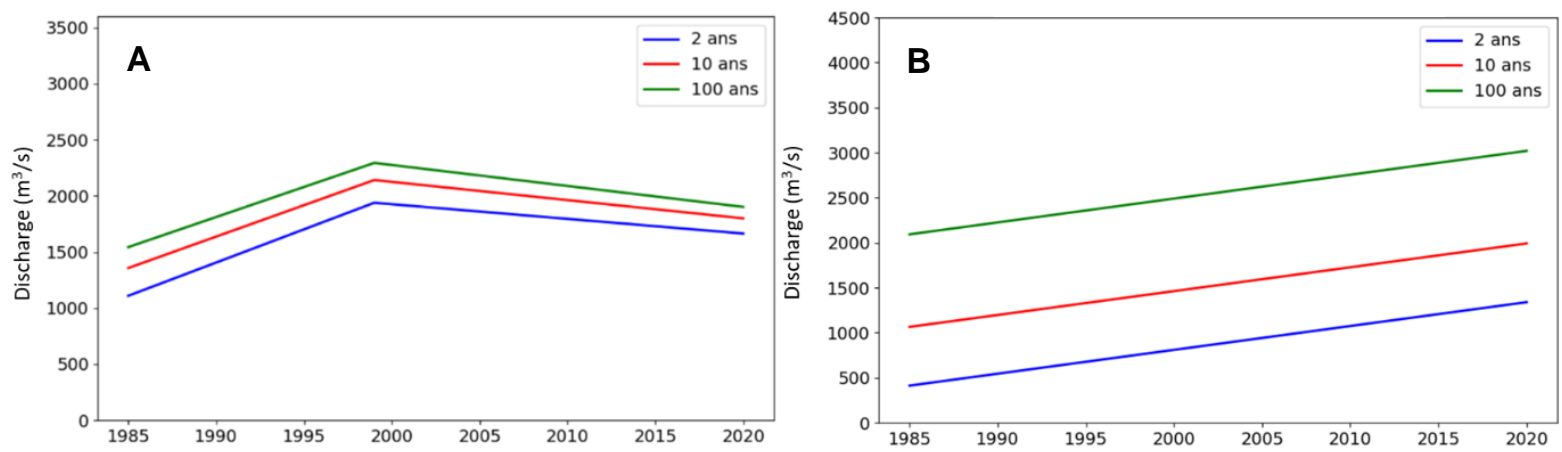

Figure 9. Evolution of return levels for three return periods (2, 10 and 100 years): (A) (left) black and (B) (right) red floods in the Niamey City. 
The consequence is that the return period of the warning levels has been decreasing sharply since 1985 (Figure 10) for the red flood.

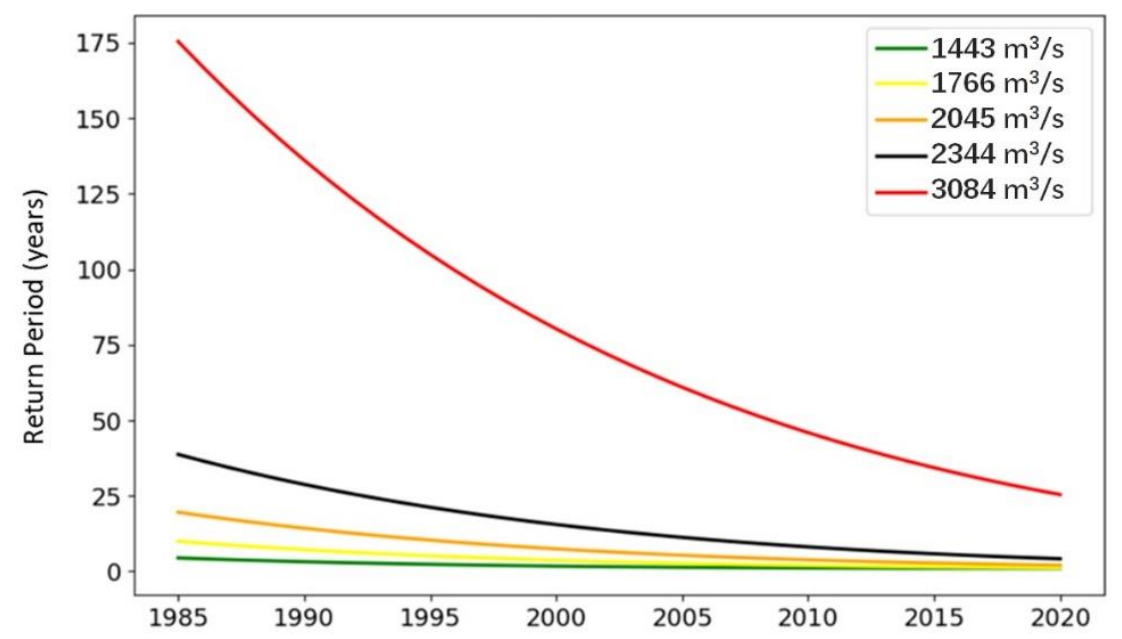

Figure 10. Evolution of return period associated to the flows of actual hazard-thresholds in the Niamey City.

The specific downward behaviour of the black flood since the late 1990s (Figure 9A) also suggests that the most critical exceedance levels for most recent years have an extremely low (orange level) or almost zero probability (TOP and red level) of being reached by the Guinean upstream discharges.

Criticalities emerged in Table 5 reflect high-risk levels empirically substantiated by flood damages $[30,59]$ caused by the red floods that occurred in Niamey in the past decades. Table 6 highlights that the six flood events recently documented in Niamey have a RP above 10 years (between 13 and 106) under stationary hypothesis. For the same events NS RP vary from 3 to 18 . As an example, the 2020 flood has a probability of occurrence of $1 \%$ under the stationary hypothesis but of $18 \%$ under NS well explaining the diverging behaviour and reflecting a dramatically increasing flood risk for the Niamey City.

Table 6. Riverine floods events and related return periods of red AMAX causing damages in Niamey in the past decades. Source of affected people: 1998-2020 BDNIA [30].

\begin{tabular}{|c|c|c|c|c|c|c|}
\hline Flood & Date & Affected People (Thousands) & $\mathrm{h}(\mathrm{cm})$ & $Q\left(\mathrm{~m}^{3} / \mathrm{s}\right)$ & RP $_{\text {RED }}$ (Year) & NS-RP $P_{\text {RED }}$ (Year) \\
\hline 1998 & 19 September & 27 & 537 & 2234 & 28 & 18 \\
\hline 2010 & 7 September & 18 & 565 & 1993 & 13 & 3 \\
\hline 2012 & 22 August & 45 & 617 & 2482 & 61 & 7.4 \\
\hline 2013 & 30 August & 65 & 611 & 2422 & 50 & 6 \\
\hline 2019 & 1 September & 6 & 636 & 2162 & 22 & 2.4 \\
\hline 2020 & 8 September & 84 & 699 & 2653 & 106 & 5.5 \\
\hline
\end{tabular}

The comparison of 1998 and 2019 events shows that, even if the discharge is quite similar in the river, a supplementary depth of $1 \mathrm{~m}$ was observed in 2019 producing a considerable enlarging of flood-prone areas. The changing behaviour of the Niamey crosssection, which produces an increase of the water level associated at the flood scenarios, could be partially related to silting up of the river bed. Minimum water levels at the Niamey station have been used as a proxy for detecting silting processes. The analysis of water levels trends shows:

- $\quad$ Significant and positive trend of daily water levels during the 1985-2020 period: $+4.24 \mathrm{~cm} /$ year;

- Significant and positive trend of AMIN depth: $+2.6 \mathrm{~cm} /$ year;

- Significant and positive trend of AMAX depth: $+6.3 \mathrm{~cm} /$ year. 
A linear regression analysis on AMIN and time/rainfall over the whole Niger River Basin (Table A1), shows that both of them are positively and significantly correlated and the time coefficient is greater (1.93) than the rainfall one (0.19) meaning that the increase in AMIN does not depend so much on rainfall (see Table A2) and it is related to the silting process. However, the discrepancy between the AMAX depth of 2019 and 1998 could not completely be explained by AMIN increase (Figure A2). Therefore, other changes in the Niger River cross-section, such as the levee construction in the Niamey reach, are probably the contributing causes.

\subsubsection{Discharge and AMAX Trends}

The analysis of mean hydrographs in Niamey: 1) confirms the new hydrological behaviour already described by several authors since the beginning of the century and 2) highlights the exceptional behaviour observed in 2012 and 2020 (Figure 11). These two flood events, even if similar in peak magnitude, are quite different regarding flood length and permanence in the red alert $\left(\mathrm{Q}>2045 \mathrm{~m}^{3} / \mathrm{s}\right)$, causing levee collapses in the city.

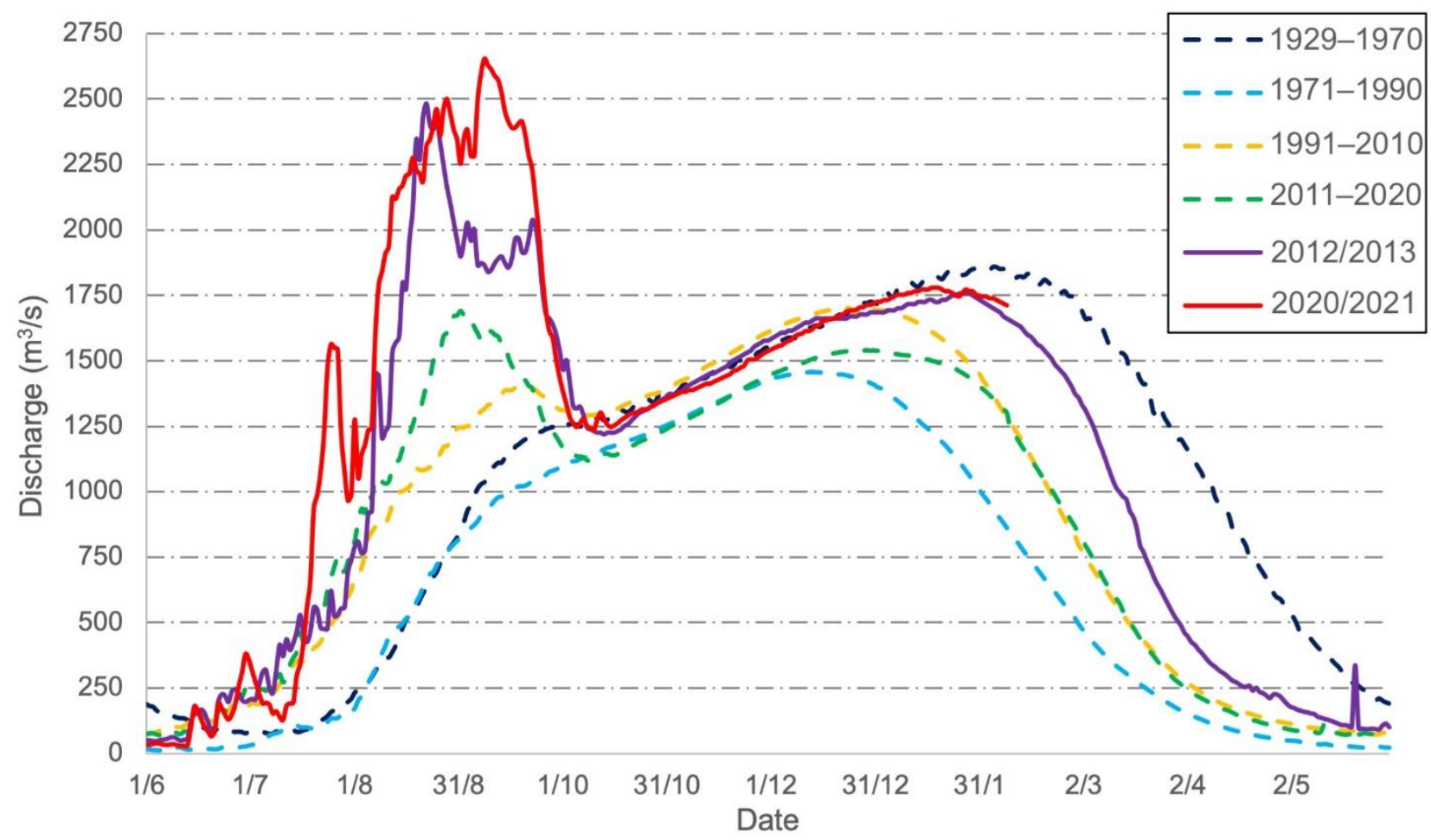

Figure 11. Mean intra-annual hydrographs (the hydrological year starts on 1 June and ends on 31 May) of Niger River in Niamey: the four hydrological periods (1929-1970, 1971-1990, 1991-2010, and 2011-2020) and the catastrophic years 2012 and 2020 .

Moreover, AMAX analysis of black and red floods confirms the results of Aich et al. [60] and Descroix et al. [15] on the general trend of red floods that are progressively becoming more important than the black one. Since 2010, a local flood stronger than the regional flood has been observed 7 years over 10 (Figure A3). Anomalies on the series have different patterns (Figure 12): for the black flood, a first period generally above normal until 1969, a decade from 1970 to 1981 on the average but contrasted interannually followed by a dry decade (1982-1993), a period from 1994 to 2010 generally above normal and the last decade below normal. The red flood was characterised by a long period until 1997 globally below the average, a period 1998-2011 slightly above the average and a last period far above normal. 


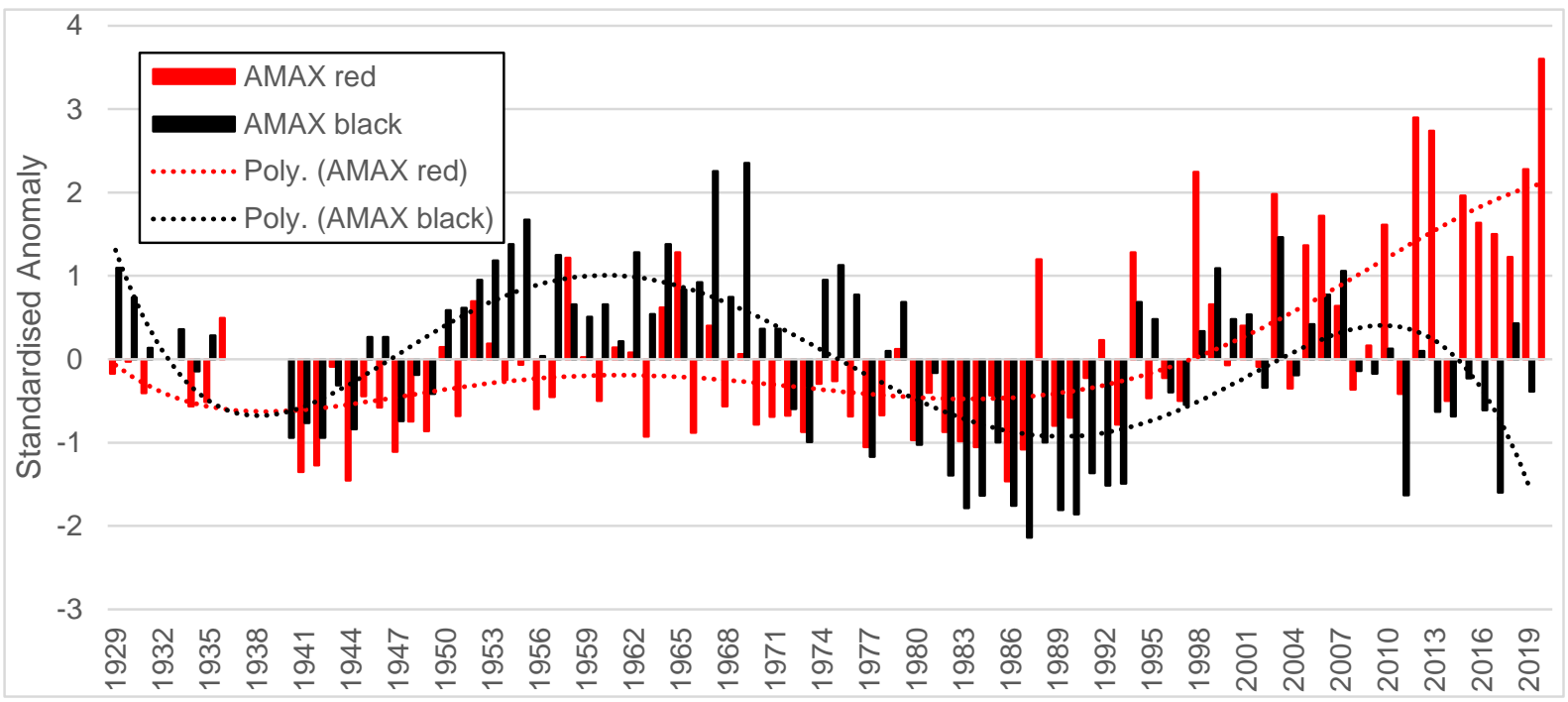

Figure 12. Anomalies of red and black flood at Niamey gauging station (1929-2020) and 5th degree polynomial interpretation.

\subsubsection{AMAX Rainfall Relation}

Even if it has been largely demonstrated that precipitation over the MNRB is not the cause of long-term observed trends in river discharge, it has a good correlation with red AMAX [6]. The analysis conducted on the updated flow and rainfall data confirms the correlation $\left(R^{2}=0.68\right)$ in the $1958-2020$ period (Table A2). The segmentation of rainfall in the MNRB is coherent with Descroix et al. [10] up to 2010 and adds a further period from 2012 to 2020 with a slightly higher average compared to the previous one (Table A3). The comparison of rainfall and red AMAX segmentation shows that, even if periods are generally different, the last 2011-2020 decade is characterised by a largely above normal behaviour for both series (Figure 13).

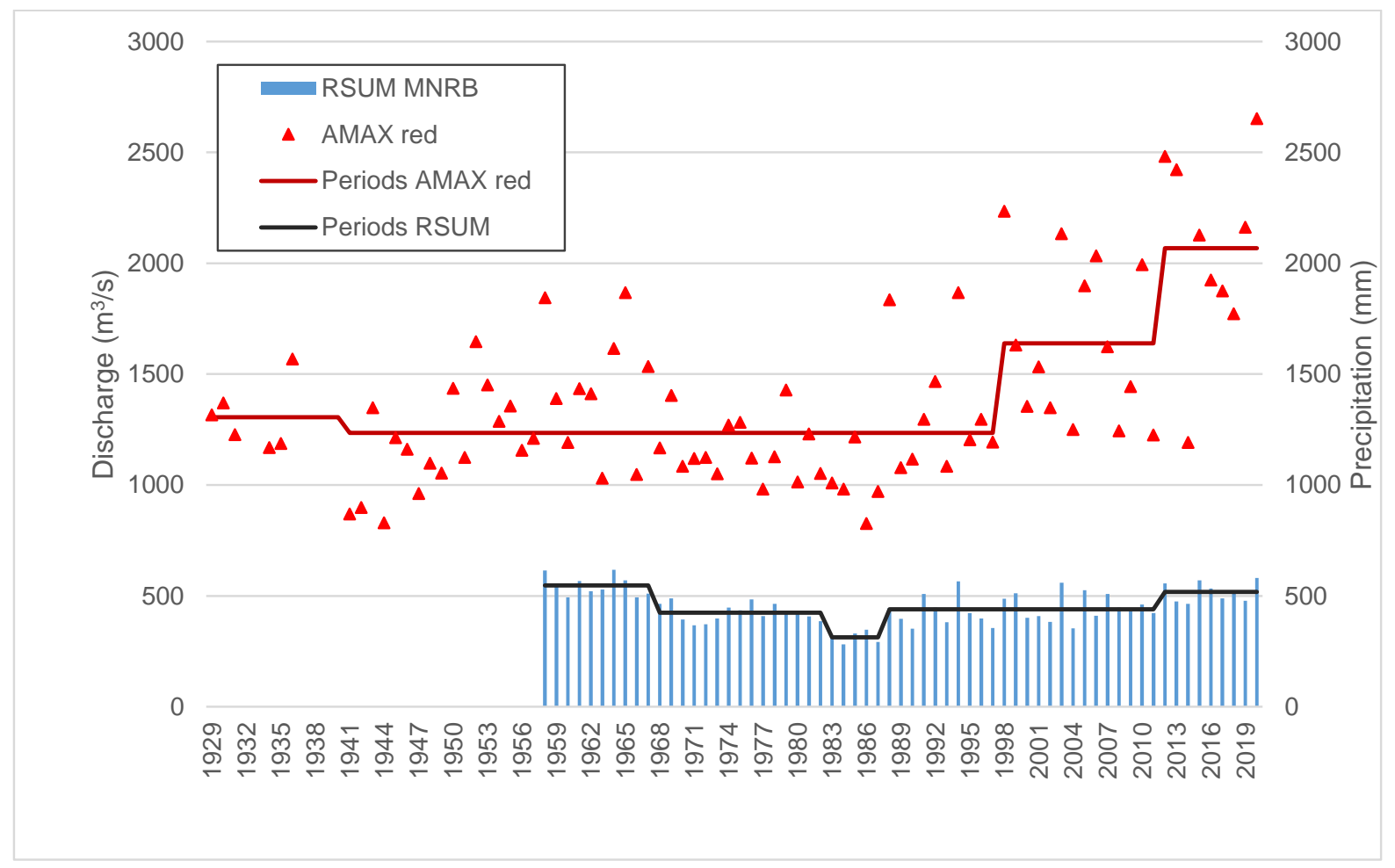

Figure 13. Red AMAX in Niamey and annual precipitation (RSUM) over the MNRB with the average of the periods (Hubert segmentation with Sheffé $1 \%$. Results of the different tests are provided in the Supplementary materials). 
Moreover, the classification in standard periods (Table 7) adequately explains the variability of AMAX and rainfall. Even if rainfall depth recovers slowly after the drought and does not reach the pre-drought depth even in the past decade, AMAX rises earlier and largely exceeds the pre-drought levels. Table 7 also highlights that while the rainfall decrease in the dry period was higher than the red AMAX one, in III and IV period the flow increase is higher than the rainfall confirming the Sahelian paradox.

Table 7. Data series segmentation (fixed periods): mean, median and difference of annual precipitation over MNRB (RSUM); mean, median of red AMAX in Niamey. For normally distributed variables, the t-student test ( $t$-test) was used. For non-normal distributed variables, the Wilcoxon-Mann-Whitney test (U-test) was used. The $\Delta_{-1}$ period is the difference (\%) between the period and the previous ones. Significance of changes: $* * *<0.01,{ }^{* *} p<0.05, * p<0.1$.

\begin{tabular}{|c|c|c|c|c|c|}
\hline Variable & Index & I: $19 . .-1970$ & II: $1971-1990$ & III: 1991-2010 & IV: 2011-2020 \\
\hline \multirow{3}{*}{ RSUM } & mean (mm) & 524 & 389 & 448 & 508 \\
\hline & median (mm) & 521 & 398 & 440 & 501 \\
\hline & $t$-test $\Delta_{-1}$ period & & $-26 \% * * *$ & $+15 \% * * *$ & $+11 \%$ ** \\
\hline \multirow{3}{*}{ Niamey red AMAX } & mean $\left(\mathrm{m}^{3} / \mathrm{s}\right)$ & 1277 & 1142 & 1557 & 1984 \\
\hline & median (mm) & 1212 & 1118 & 1455 & 2025 \\
\hline & U test -1 period & & $>^{* *}$ & $<* * *$ & $<* *$ \\
\hline
\end{tabular}

Since AMAX data series are not normally distributed, the quintile regression (Table 8 ) is used to show the significative differences in medians. The last decade results are statistically different from all the previous periods.

Table 8. Data series segmentation (fixed periods): Quantile regression of red AMAX in Niamey. Difference in medians among periods and standard errors (in parentheses). Significance of changes: ${ }^{* *} p<0.01,{ }^{* *} p<0.05,{ }^{*} p<0.1$.

\begin{tabular}{|c|c|c|c|c|}
\hline Niamey red AMAX & I: 1941-1970 & II: 1971-1990 & III: 1991-2010 & IV: 2011-2020 \\
\hline I: $1941-1970$ & - & $\begin{array}{c}93.510 \\
(125.477)\end{array}$ & $\begin{array}{c}-254.040^{* *} \\
(125.477)\end{array}$ & $\begin{array}{c}-710.390 * * * \\
(158.718)\end{array}$ \\
\hline II: $1971-1990$ & $\begin{array}{c}-93.510 \\
(125.477)\end{array}$ & - & $\begin{array}{c}-347.550 * * \\
(137.454)\end{array}$ & $\begin{array}{c}-803.900 * * * \\
(168.346)\end{array}$ \\
\hline III: 1991-2010 & $\begin{array}{c}254.040^{* *} \\
(125.477)\end{array}$ & $\begin{array}{c}347.550 * * \\
(137.454)\end{array}$ & - & $\begin{array}{c}-456.350 * * * \\
(168.346)\end{array}$ \\
\hline IV: 2011-2020 & $\begin{array}{c}710.390 * * * \\
(158.718)\end{array}$ & $\begin{array}{c}803.900 * * * \\
(168.346)\end{array}$ & $\begin{array}{c}456.350 * * * * \\
(168.346)\end{array}$ & - \\
\hline Constant (median) & $\begin{array}{c}1213.510^{* * *} \\
(79.359)\end{array}$ & $\begin{array}{c}1120.000^{* * *} \\
(97.194)\end{array}$ & $\begin{array}{c}1467.550^{* * *} \\
(97.194)\end{array}$ & $\begin{array}{c}1923.900 * * * \\
(137.454)\end{array}$ \\
\hline
\end{tabular}

\subsubsection{Sahelian Tributaries Behaviour}

The discharge evolution of Sahelian tributaries (Figure 14) shows: (1) a marked changing behaviour in the four periods according to regional hydroclimatic changes, (2) an early river peak, since the II period, compared to the first one (the flood peak occurred about 20 days earlier), (3) a longer flood peak in the Sirba river and a sharper one in the other tributaries, (4) a similar response of the three basins from II to III period and (5) a significant and more marked increase from III to IV period in the Sirba River compared to the other tributaries. The evolution of mean hydrographs of Sahelian tributaries explains the red flood increase observed in Niamey (Figure 9A). It is important to underline that: (1) the Gorouol behaviour in IV period was most likely underestimated since the lack of 2019 and 2020 observations and (2) Kakassi and Alcongui levels could not be perfectly converted in flows since the outdated rating curves adopted for stage-discharge conversion. 


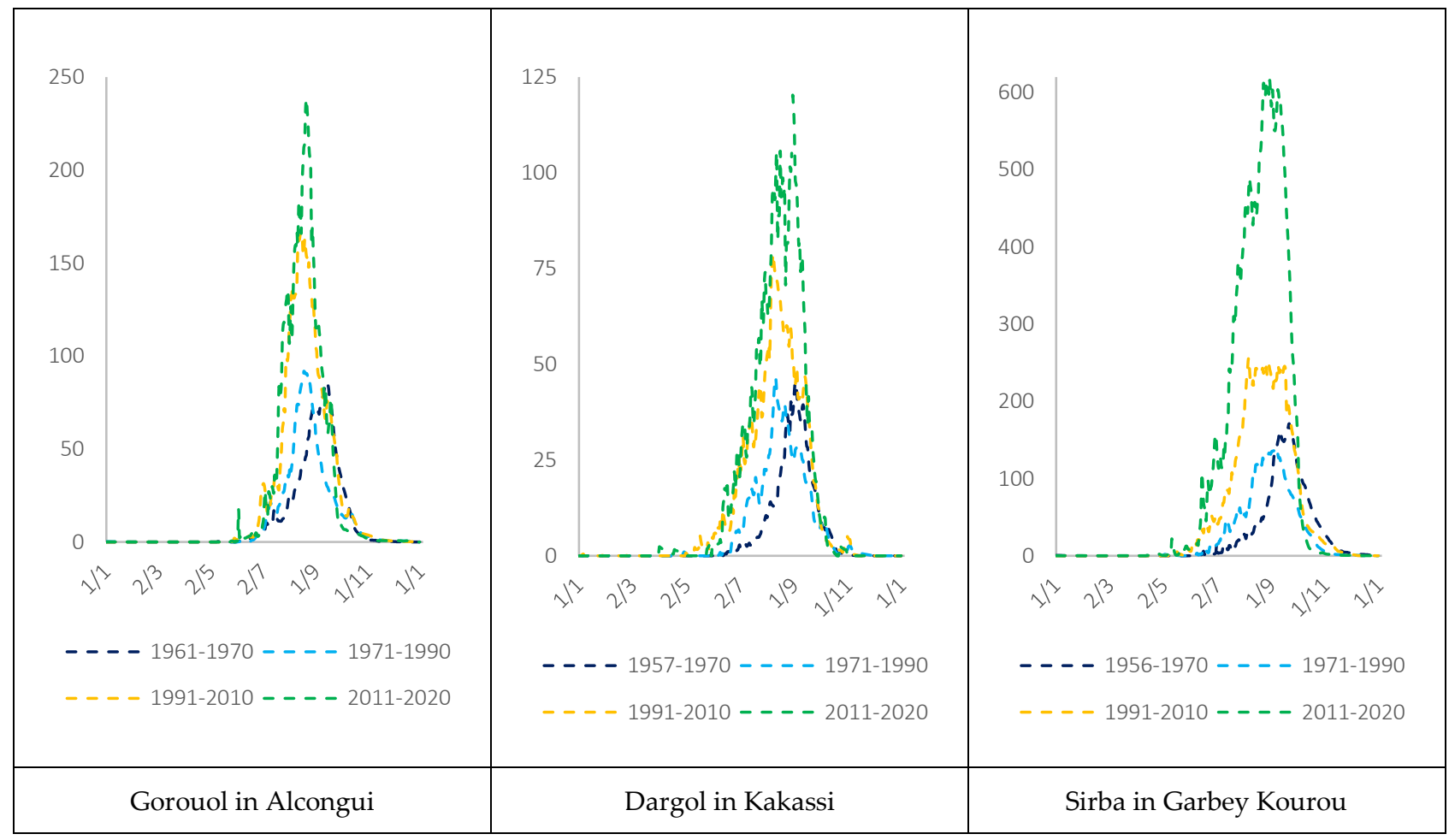

Figure 14. Intra annual mean hydrographs $\left(\mathrm{m}^{3} / \mathrm{s}\right)$ of the main Sahelian basins (Gorouol, Dargol and Sirba rivers) in the four hydrological periods (I:19..-1970, II:1971-1990, III:1991-2010 and IV: 2011-2020).

The behaviour of AMAX on Sahelian tributaries does not show statistically relevant differences up to 1990, while the two following periods are clearly and significantly rising. Table 9 underlines that: (1) The AMAX magnitude reflects basin area and latitude rainfall decrease; (2) the AMAX normalised with the basin area is considerably larger in Dargol, while Sirba has values with a magnitude similar to the n-1 period in Dargol and finally Gorouol has significantly lower values; (3) the AMAX increase from II to III period is very relevant in the three basins and (4) the AMAX increase from III to IV period is still strong in the Sirba and Dargol Rivers while it weakens in Gorouol.

The RC analysis confirms an important increase in runoff especially for Sirba and Dargol, while the trend of Gorouol at Alcongui is slightly less steep. Trends are statistically significant $\left(R^{2}>0.4\right.$ and $p$ value $\left.<0.01\right)$ for all tributaries. The $R C$ s calculated by this study are different from those already published $[10,15]$ for the Sirba basin because of the updating of the rating curve and, for the Gorouol, because the basin area was recalculated. The Dargol series was only updated with the five most recent years. Table 10 highlights that the maximum RC increase was reached in the III period while in the IV period the increase reached a lower rate. The deceleration of the RC increase is very strong in Dargol and strong in Gorouol and not yet observed in Sirba. 
Table 9. Data series segmentation (fixed periods): mean, median and difference of AMAX of the main Sahelian tributaries. For non-normal distributed variables, the Wilcoxon-Mann-Whitney test (U-test) and the quantile regression (Qreg) were used. The $\Delta_{-1}$ period is the difference (\%) between the period and the previous ones. Significance of changes: ${ }^{* * *} p<0.01$, ${ }^{* *} p<0.05, * p<0.1$. (\#the flow time series of Gorouol stops in 2018).

\begin{tabular}{|c|c|c|c|c|c|}
\hline Basin & Index & I: $19 . .-1970$ & II: $1971-1990$ & III: $1991-2010$ & IV: $2011-2020$ \\
\hline \multirow{5}{*}{ Sirba AMAX } & mean $\left(\mathrm{m}^{3} / \mathrm{s}\right)$ & 225 & 225 & 431 & 863 \\
\hline & mean $\left(1 / \mathrm{km}^{2}\right)$ & 5.76 & 5.76 & 11.02 & 22.07 \\
\hline & median $\left(\mathrm{m}^{3} / \mathrm{s}\right)$ & 194 & 166 & 409 & 866 \\
\hline & U test -1 period & & & $<* * *$ & $<* * *$ \\
\hline & Qreg $\Delta_{-1}$ period & & $-14 \%$ & $147 \% * * *$ & $111 \%$ ** \\
\hline \multirow{5}{*}{ Dargol AMAX } & mean $\left(\mathrm{m}^{3} / \mathrm{s}\right)$ & 73 & 70 & 134 & 218 \\
\hline & mean $\left(1 / \mathrm{km}^{2}\right)$ & 10.21 & 9.79 & 18.74 & 30.48 \\
\hline & median $\left(\mathrm{m}^{3} / \mathrm{s}\right)$ & 57 & 65 & 128 & 269 \\
\hline & U test -1 period & & & $<* * *$ & $<* *$ \\
\hline & Qreg $\Delta_{-1}$ period & & $13 \%$ & $98 \% * * *$ & $110 \% * * *$ \\
\hline \multirow{5}{*}{ Gorouol AMAX } & mean $\left(\mathrm{m}^{3} / \mathrm{s}\right)$ & 125 & 143 & 244 & 304\# \\
\hline & mean $\left(1 / \mathrm{km}^{2}\right)$ & 2.36 & 2.70 & 4.60 & $5.74 \#$ \\
\hline & median $\left(\mathrm{m}^{3} / \mathrm{s}\right)$ & 93 & 121 & 192 & $237 \#$ \\
\hline & U test-1 period & & & $<* * *$ & \\
\hline & Qreg $\Delta_{-1}$ period & & $30 \%$ & $59 \%$ & $24 \% \#$ \\
\hline
\end{tabular}

Table 10. Data series segmentation (fixed periods): mean, median and difference of RC of the main Sahelian tributaries. For non-normal distributed variables, the Wilcoxon-Mann-Whitney test (U-test) and the quantile regression (Qreg) were used. The $\Delta_{-1}$ period is the difference ( $\left.\%\right)$ between the period and the previous ones. Significance of changes: ${ }^{* * *} p<0.01,{ }^{* *} p<0.05$, * $p<0.1$. (\#the flow time series of Gorouol stops in 2018).

\begin{tabular}{|c|c|c|c|c|c|}
\hline Basin & Index & I: $19 . .-1970$ & II: 1971-1990 & III: 1991-2010 & IV: 2011-2020 \\
\hline \multirow{4}{*}{ Sirba RC } & mean (\%) & 2.6 & 3.4 & 6.9 & 12.5 \\
\hline & median (\%) & 3.2 & 2.9 & 7 & 12.2 \\
\hline & $\mathrm{U}$ test -1 period & & & $<* * *$ & $<* * *$ \\
\hline & Qreg $\Delta_{-1}$ period & & $-9 \%$ & $141 \%$ *** & $74 \% * *$ \\
\hline \multirow{4}{*}{ Dargol RC } & mean $(\%)$ & 4.1 & 6.7 & 11.2 & 13.6 \\
\hline & median (\%) & 4 & 6.7 & 11.1 & 13.2 \\
\hline & $\mathrm{U}$ test -1 period & & $<* *$ & $<* * *$ & \\
\hline & Qreg $\Delta_{-1}$ period & & $+65 \% * *$ & $+67 \% * * *$ & $+19 \%$ \\
\hline \multirow{4}{*}{ Gorouol RC } & mean (\%) & 1.5 & 2.1 & 3.2 & $3.4 \#$ \\
\hline & median (\%) & 1.4 & 1.7 & 2.7 & $3.5 \#$ \\
\hline & U test -1 period & & & $<* *$ & \\
\hline & Qreg $\Delta_{-1}$ period & & $+14 \%$ * & $+65 \% * *$ & $+30 \% \#$ \\
\hline
\end{tabular}

The RC trends were analysed in detail in Figure 15, where the trend was simulated towards polynomial curves of 3rd degree, facilitating the comprehension over time. The Dargol and Sirba trends are similar even if Dargol rose earlier (in 1958 the trend line was already around $4 \%$ ) than Sirba (whose trend line reached $4 \%$ in 1988) but the increase in the last period is not significant (Table 10). Both show increasing inter-annual variability, which is less clear on Gorouol. The latter shows a trend that forces the hypothesis that a RC plateau was reached with a slightly decreasing behaviour during the last decade. Gorouol is the northern and larger basin receiving less rainfall than the others, it is less anthropized and some parts of the basin are probably still endorheic. RC is actually around $4 \%$ with averages during the different periods not significantly changing. Dargol trend shows an inflection point around 2010 that induces the hypothesis that a plateau will be reached in the next few years. The Sirba trend is not at all characterised by inflection points and, since 2018 the divergent behaviour makes the Sirba RCs greater than the Dargol ones. 


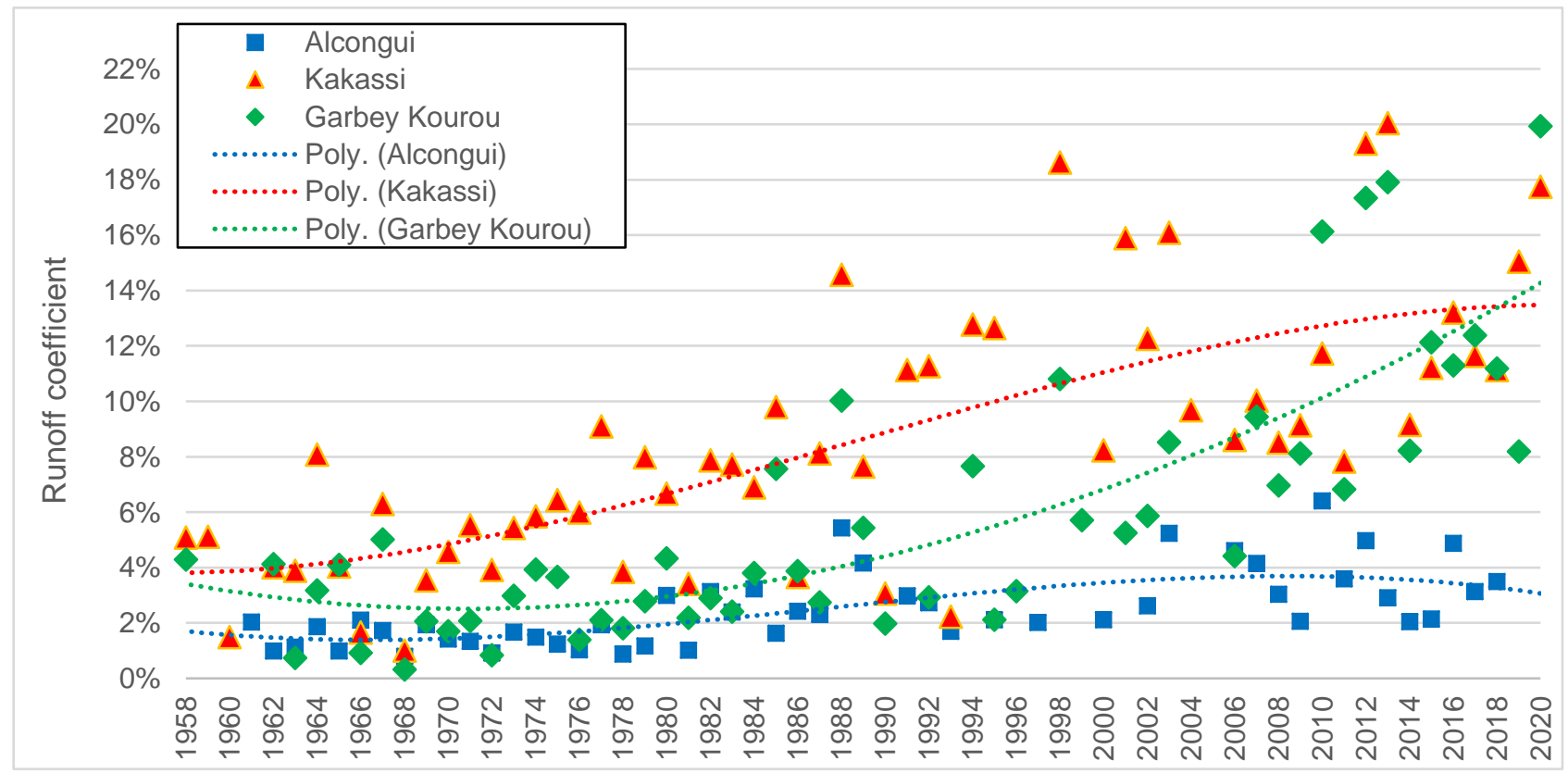

Figure 15. Runoff coefficients over the period 1958-2020 of the three main Sahelian tributaries: Gorouol River at Alcongui, Dargol River at Kakassi and Sirba River at Garbey Kourou.

In conclusion, in MNRB the last decade is marked by high positive anomalies of hydrological (both annual mean values and extremes) and precipitation (annual mean values) on the longer data series. Therefore, a further research question arises: the hydrological extremes observed during the last decade, even if part of a long-term trend having its grassroot causes in landscape changes, can be explained by climatic variability?

\subsection{Precipitation Analysis}

To better understand the behaviour of the last years, precipitation indexes (Table A4) on the shorter time series (CHIRPS) are related to Niamey red flood AMAX. Climatically (Table 11), the last decade is clearly characterised by:

- An increase of cumulated precipitation, even if with a growth rate lower than in the previous period.

- A strong increase of extremes, which had not increased from period II to period III.

Table 11. Data series segmentation (fixed periods): mean and difference of rainfall indexes over MNRB. For normally distributed variables the t-Student test ( $t$-test) is showed while for non-normal distributed variables, the Wilcoxon-Mann-Whitney test (U-test) is showed. Significance of changes: *** $p<0.01,{ }^{* *} p<0.05, * p<0.1$.

\begin{tabular}{|c|c|c|c|c|}
\hline Rainfall Index & Unit & II 1981-1990 & III 1991-2010 & IV 2011-2020 \\
\hline \multirow{2}{*}{ RSUM } & mean $(\mathrm{mm})$ & 355.69 & 432.21 & 480.26 \\
\hline & $t$-test $\Delta_{-1}$ period & & $22 \% * * *$ & $11 \%$ ** \\
\hline \multirow{2}{*}{ RR1 } & mean (days) & 43.67 & 51.08 & 53.40 \\
\hline & $t$-test $\Delta_{-1}$ period & & $17 \% * * *$ & $5 \%$ \\
\hline \multirow{2}{*}{ SDII } & mean (mm/day) & 7.95 & 8.28 & 8.83 \\
\hline & $t$-test $\Delta_{-1}$ period & & $4 \%$ & $7 \% *$ \\
\hline \multirow{2}{*}{ N_days_95C } & mean (days) & 2.18 & 2.22 & 3.35 \\
\hline & $t$-test $\Delta_{-1}$ period & & $2 \%$ & $51 \%^{* * *}$ \\
\hline \multirow{2}{*}{ N_days_95C_08 } & mean (days) & 1.24 & 1.18 & 2.10 \\
\hline & $t$-test $\Delta_{-1 \text { period }}$ & & $-5 \%$ & $78 \% * * *$ \\
\hline
\end{tabular}


Table 11. Cont.

\begin{tabular}{|c|c|c|c|c|}
\hline Rainfall Index & Unit & II 1981-1990 & III 1991-2010 & IV 2011-2020 \\
\hline \multirow{2}{*}{ Rain_95C } & mean (mm) & 63.97 & 59.78 & 91.88 \\
\hline & U test -1 period & & & $<* * *$ \\
\hline \multirow{2}{*}{ Contrib_95C } & mean $(\%)$ & 0.17 & 0.13 & 0.18 \\
\hline & $\mathrm{U}$ test -1 period & & & $<* * *$ \\
\hline \multirow{2}{*}{ MAX1 } & mean (mm) & 29.94 & 28.06 & 31.13 \\
\hline & $t$-test $\Delta_{-1}$ period & & $-6 \%$ & $11 \% * *$ \\
\hline \multirow{2}{*}{ MAX5 } & mean $(\mathrm{mm})$ & 52.76 & 53.76 & 61.91 \\
\hline & $t$-test $\Delta_{-1 \text { period }}$ & & $2 \%$ & $15 \%$ *** \\
\hline
\end{tabular}

Within this new behaviour, 2020 appears as a paroxysmal year in terms of precipitation amount and extreme rainfall events: except for the number of rainy days, all other indexes show normalised values above 2 (Figure 16).

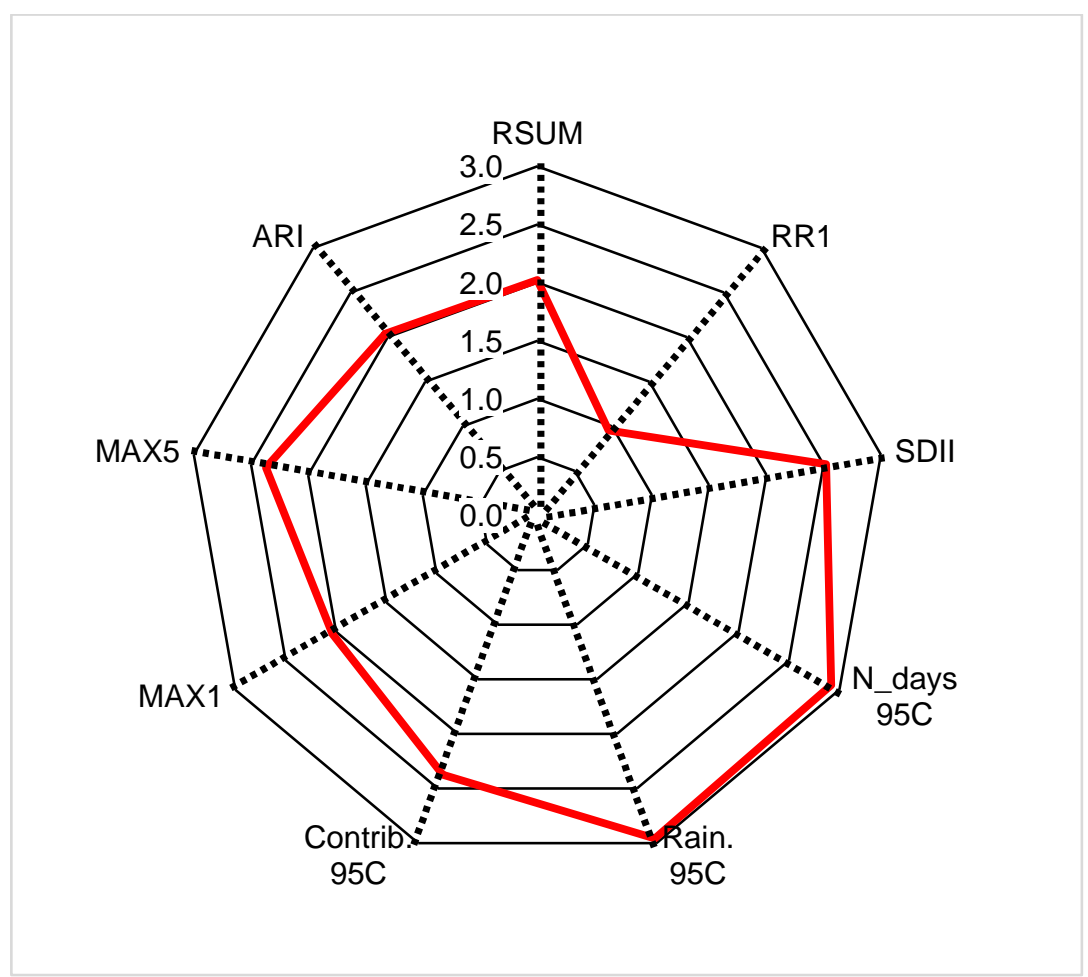

Figure 16. Anomalies of rainfall indices in 2020 rainy season over MNRB (Normal = 0).

The correlation between red AMAX and rainfall indexes (Table 12) clearly shows that cumulated rainfall has the stronger significant correlation on the entire 1981-2020 series and in II and III periods but during the last one some indices related to extremes (number of days above 95 centile and cumulated rainfall of days above the 95 centile) have a better one both in terms of coefficients and significance. 
Table 12. Correlation matrix between red AMAX and rainfall indexes over MNRB. Pearson correlation coefficients and their significance level: ${ }^{* *} p<0.01,{ }^{* *} p<0.05,{ }^{*} p<0.1$.

\begin{tabular}{ccccc}
\hline & 1981-2020 & II 1981-1990 & III 1991-2010 & IV 2011-2020 \\
\cline { 2 - 5 } & AMAX & AMAX & AMAX & AMAX \\
\hline RSUM & $0.8296^{* * *}$ & $0.7037^{* *}$ & $0.7796^{* * *}$ & $0.7122^{* *}$ \\
RR1 & $0.7506^{* * *}$ & $0.6036^{*}$ & $0.7064^{* * *}$ & $0.6051^{*}$ \\
SDII & $0.6372^{* * *}$ & 0.5423 & $0.5148^{* *}$ & 0.4771 \\
N_days_95C & $0.7058^{* * *}$ & $0.648^{* *}$ & $0.6138^{* * *}$ & $0.7832^{* * *}$ \\
Contrib_95C & $0.4^{* *}$ & 0.4943 & $0.4092^{*}$ & $0.7279^{* *}$ \\
Rain_95C & $0.6392^{* * *}$ & $0.5993^{*}$ & $0.5884^{* * *}$ & $0.7666^{* * *}$ \\
MAX1 & $0.3298^{* *}$ & $0.4264^{* *}$ & $0.3855^{*}$ & 0.4974 \\
MAX5 & $0.6427^{* * *}$ & $0.6776^{* *}$ & $0.6052^{* * *}$ & $0.5595^{*}$ \\
\hline
\end{tabular}

When analysing years with red AMAX positive anomalies ( $>1$ st.dev) at Niamey hydrometer (Table 13) — to be noted that 5 years out of 7 are placed in the last period —-three different behaviours are observed, which can be explained by the combination of rainfall indexes:

- In 2020, 2012, 1998 and 2015, the total amount of precipitation and the intensity of the extreme episodes in the MNRB were significantly above the average. 2020 and 2012 have been two exceptional years while 1998 was characterised by an abnormal quantity of extreme rainy days in September and in that year there were 12 days with water level above the red alert threshold only in September.

- In 2003, only the amount of precipitation was above normal.

- In 2013 and 2019, most indexes were around normal, except a large above-normal concentration of days above the 95th percentile in August and a below-normal concentration in July and September. These conditions were harbingers of sharp but intense flood peaks between the end of August and the beginning of September.

Table 13. Anomalies of red AMAX and extreme rainfall indexes for years with red AMAX anomaly $>1$ st.dev (sorted by Red AMAX).

\begin{tabular}{|c|c|c|c|c|c|c|c|c|c|c|}
\hline Year & $\begin{array}{c}\text { Red } \\
\text { AMAX }\end{array}$ & RSUM & SDII & N_Days_95C & $\begin{array}{c}\text { N_Days_95C } \\
\text { July }\end{array}$ & $\begin{array}{c}\text { N_Days_95C } \\
\text { August }\end{array}$ & $\begin{array}{c}\text { N_Days_95C } \\
\text { Sept. }\end{array}$ & MAX1 & MAX5 & ARI \\
\hline 2020 & 2.33 & 2.02 & 2.52 & 2.92 & 0.38 & 3.06 & 1.48 & 2.04 & 2.37 & 2.04 \\
\hline 2012 & 1.96 & 1.74 & 1.59 & 1.70 & -0.04 & 1.68 & 1.88 & 0.73 & 1.82 & 1.80 \\
\hline 2013 & 1.84 & 0.27 & -0.67 & 0.26 & -0.76 & 1.08 & -0.91 & -0.11 & 0.23 & 0.30 \\
\hline 1998 & 1.44 & 1.17 & 1.04 & 1.15 & 1.48 & -0.44 & 3.41 & 0.62 & 0.23 & 1.15 \\
\hline 2019 & 1.29 & 0.57 & 0.00 & 0.91 & -0.46 & 1.85 & -1.04 & 0.78 & 1.03 & 0.53 \\
\hline 2003 & 1.23 & 1.49 & 0.72 & 0.57 & 1.00 & -0.16 & 0.79 & 0.03 & 0.10 & 1.35 \\
\hline 2015 & 1.21 & 1.05 & 1.13 & 1.15 & 3.66 & -0.19 & -0.66 & 0.17 & 0.70 & 1.02 \\
\hline
\end{tabular}

In general, August shows a strong trend over the different periods in the number of extreme events which are a further driver of high AMAX (Figure A4).

Contrariwise to the highest red AMAX, the years with the lowest red AMAX (Anomaly $<-1$ st.dev) are concentrated in the 1982-1989 period and all have an annual cumulative precipitation largely below the average (Table A5).

In conclusion, climatic features of the last period correctly explain the intra-annual variability of hydrological extremes in the MNRB.

\section{Discussion}

\subsection{A New Hydrological Era?}

A recent press article of Lebel et al. [61] advocates for the beginning of a new hydroclimatological era in the Sahel, which was already hypothesised by Descroix et al. in 2018 [15]. The new patterns of hydrological response are attributed to the combined effect 
of increased rainfall (amount and intensity) and changes in LULC, bringing to higher floods exacerbated by groundwater upwelling and riverbed silting.

Time series analyses of all indicators, both hydrological and climatic, indicate that the last decade has a completely new configuration compared both to the recent past after the drought and also to the pre-drought period when, nevertheless, the annual cumulated precipitation was still higher than in the last decade (Table 7). The main climatic feature of the current period compared to the last, rather than a moderate increase of annual precipitation, is the net and significant increase of extreme events and their concentration in the month of August.

Hydrologically, the rise of Sahelian tributaries' RC and AMAX caused an impressive series of positive anomalies of Niamey red AMAX producing damaging flood events (2010, 2012, 2013, 2019 and 2020). The long-term trend of red AMAX, despite having its underlaying driver in soil surface changes, is significantly correlated with the annual rainfall amount over the MNRB, while intense AMAX of the last decade are also significantly correlated to the precipitation extremes' and their distribution at a monthly scale (Table 12). The integrated use of TC and CHIRPS v2 gridded datasets resulted a valuable approach for hydroclimatic studies in territories characterised by weak rainfall observation networks.

The convergence of positive climatic anomalies with the rise of RC suggests a multiplier effect, for the coming years, that could induce a steeper increase of hydrological parameters along the Sirba and in Niamey. Nevertheless, the analysis of RC evolution in the Sahelian basins suggests that in Gorouol a plateau has been reached since 2010 and is also imminent in the Dargol (Figure 15). It is also worth noting that, since 2018, the RC of Sirba exceeded the Dargol one that was significantly higher since the beginning of flow monitoring in the 1950s. Contrary to what Wilcox et al. [12] observed, Sirba actually shows the higher runoff increase among the Sahelian tributaries both in terms of RC, AMAX and annual mean discharge. The updating of the rating curve can explain such a divergence [26].

The three Sahelian tributaries could represent different stages of the Sahelian paradox evolution. Gorouol, the northern one, less inhabited and mainly pastoral 'fully benefited from the rainfall increase over the last three decades, showing a global pattern of vegetation regeneration after the droughts' [17]. Despite small-scale landscape degradations which could still lead to relevant modifications in the hydrological processes, at basin scale runoff and precipitation grow accordingly. In Dargol basin, where anthropogenic factors are stronger and intense, LULC changes occurred between 2000 and 2013 [62] and a lower vegetation recovery was observed [23]. Nevertheless, the strong deceleration of RC increases in the last period suggesting that runoff increase is currently driven mainly by rainfall. The Sirba basin behaviour still responds to the first Sahelian Paradox because flow growth surpasses the precipitation one. Some studies in northern Burkina Faso show that LULC changes were still ongoing during the first decade of the 21st century [62] bringing soil surface changes, but to our best knowledge no published study has analysed LULC changes during the last decade. Descroix et al. [15] highlighted in a bibliographic review that this region was poorly affected by the regreening. This was confirmed by Brandt el al. [23], whose mapping shows that the Sirba basin is affected by one of the two spots where herbaceous mass and woody foliage vegetation were decreasing from 1992 to 2012. Conversely, after 2010, the basin does not show any trend, neither in vegetation optical depth derived from low-frequency passive microwaves (a proxy for aboveground carbon density), nor in net changes in carbon density [63]. The essence of these different researches seems to be that most of the LULC changes in the Sirba basin were effective before 2010 and that land cover showed fewer evolutions in this area since then, a period characterised by the exacerbation of streamflow and flooding events at Niamey. Therefore, the RC is still growing but the observed dynamics in the other tributaries could suggest that an inflection point could be reached next decades with the end of the Sahelian paradoxes. The time lag in reaching the inflection point of RCs rise could be related to the latitudinal gradient, the 
level of anthropisation and therefore LULC changes and also to the extension of the basins because of the scale effect [64].

Our research concludes that, even if long-term trends in discharge and RCs in MNRB are driven mainly by anthropogenic factors, red AMAX variability and frequency of floods in Niamey during the last ten years are mainly driven by climatic factors. Nevertheless, other contributing features identified in the literature are hereafter discussed.

\subsection{Silting-Up of the River Bed}

Several authors state that the silting up of the river bed is one of the main drivers of the increase in floods in Niamey $[23,25,28,61,65]$. Although there are studies in the literature on sediment transport [25] and on the morphological changes of the alluvial fans of some koris near Niamey [23,65], to our best knowledge no study demonstrates whether the Niger riverbed near Niamey is really gradually silting up. The results of Amogu [25] indicate that as the Niger crosses the Sahel, the suspended sediment flux increases and reaches a maximum around Niamey due to tributaries while in-channel or overbank deposition occurs downstream Niamey. Mamadou [65] studied the evolution of the Niger riverbed in conjunction with the alluvial fans of two koris (Boubon and Gorou Kirey) upstream of Niamey between 2008 and 2010 and observed net reduction of the river depth. But these results are far from demonstrating a generalised silting up of the river thalweg. The aforementioned authors bear witness mainly with photographic evidence of the formation of sandbanks or alluvial fans. However, the processes of sedimentation or erosion are determined by the sediment transport capacity of the river depending on the flow, channel slope, width, depth and roughness. Both processes can act at the same time in different sections of the river and in the same reach in different hydrological periods. The Niger River, entering in Niger country has a low sediment load, because of sedimentation that occurred in the inner delta, and a low flow velocity. The Sahelian right bank tributaries produce high sediment inflow into the Niger River, thus increasing sediment concentrations at Niamey, from low values during low flow conditions to remarkably high values of 4000 $\mathrm{mg} / 1$ during the red flood [25]. It is during these floods that the most sediment transport occurs, both as suspension load and bed load. The latter causes the displacement of point bars through the river channel. In sections with high sediment input, such as where the Gorouol, Dargol and Sirba Rivers join the Niger River, the river bed rises due to sediment depositing. Afterwards, when a high discharge occurs with a low sediment load (black flood), sediment deposits are flushed out, restoring balance between river bed erosion and aggradation. Amogu [25] analysed the channel morphological changes between 1989 and 1999 hence illustrating that with an increasing river discharge the channel area and channel width increased with a slight decrease in total island area, highlighting a time lag between external factors and channel response. The comparison of satellite images from 2002 until 2020 (Figure 17) shows that larger-scale features of the river channel near Niamey have not changed much in time, suggesting that a sedimentation-flushing equilibrium has been already reached. The larger mid-channel bars seem to remain stable in time, whereas smaller point bars and mid-channel bars may temporarily form and disappear (Figure 17).

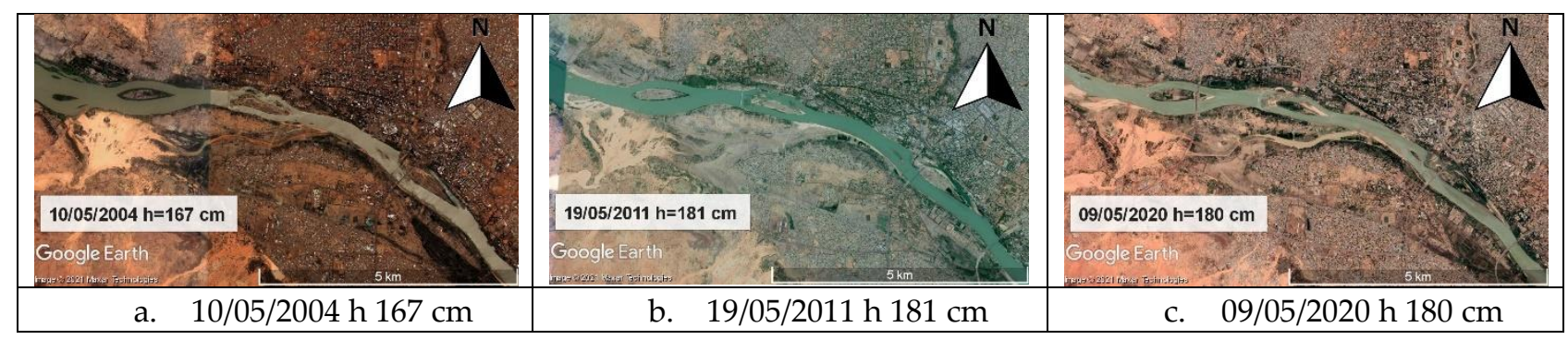

Figure 17. Evolution of the Niger river main channel in Niamey between 2004 and 2020. 
The alluvial fans of small koris upstream (Kourtéré for instance, on the left in Figure 17a-c) showed a dramatic increase since the 1980s [24,65] but have not changed so much since 2002. Conversely, the urban drainage channel of 'Palais de Congrès' shows a clear strong increase of the fan between 2002 and 2020 (Figure 18a-c between the bar and the bridge) which can partially obstruct the discharge at low water level but probably has small relevance in high water levels.

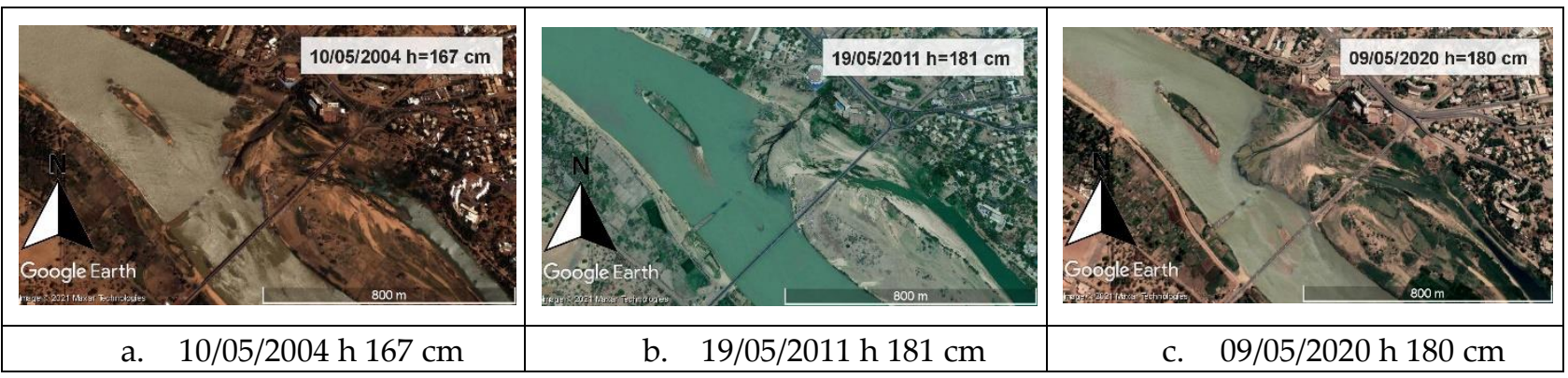

Figure 18. Evolution of the alluvial fan of the 'Palais de Congrès' channel (between the bar and the bridge).

Nevertheless, sand deposition occurred in the main channel upstream the Goudel weir causing serious drinking water supply problems to the Niamey City [65]. Gauging measures at low water levels compared with the previous rating curve (Figure 8 and Table 5) suggest that the silting of the riverbed is not at all a cause of increasing frequency and magnitude of discharges in Niamey but it is a contributing factor of the local response of flow-depth distribution into the riverbed.

\subsection{Levees and Flood Risk for Urban Areas}

Another factor affecting the rating curve are the levees, built since the past century but extended, consolidated or raised after the 2012 flood. The gauging measures for high water levels suggest that between 580 and $650 \mathrm{~cm}$ there is a 'levee effect upon flood levels' [66]. When the water reaches the base of the embankment, the level rises more than discharge. Figure 8 shows the stage divergence increasing above bankfull, but then, the stages converge again on the levee crest until $690 \mathrm{~cm}$ and diverge above this level when larger discharges flow behind the levees. The top boundary limits of the rating curve application were fixed at $700 \mathrm{~cm}$, limiting flow monitoring of the Niger River in Niamey for exceptional flows. A new campaign of high-flow ( $>7 \mathrm{~m}$ ) ADCP measurements or the implementation of a detailed hydraulic numerical model will allow to correctly evaluate the discharge above this threshold.

The Niamey levees demonstrated to be effective to limit the fluvial flooding for average stream flows but appeared insufficient to contain the high water levels of the 2019 and 2020 red floods. Moreover, return periods of hazard scenarios used in Niamey, updated with the new rating curve, suggest that peak flows will increase even more often to above-levee levels, increasing flood risk in the floodplains. Thus, there is a need to use non-stationary return periods in hydraulic infrastructures design.

Another type of 'levee-effect' is observed comparing (Figure 19) the flood event of $22 / 8 / 2012\left(617 \mathrm{~cm}\right.$ for $\left.2482 \mathrm{~m}^{3} / \mathrm{s}\right)$ with the flood of $08 / 09 / 2020\left(699 \mathrm{~cm}\right.$ for $\left.2653 \mathrm{~m}^{3} / \mathrm{s}\right)$. It refers to the paradox that the construction of protection levees might increase the potential damages in case of levee breakage because they encourage new development and settlement in the floodplain [67]. That is the case of Niamey, where the failure-because of improper sizing and lack of maintenance [68] — of levees, raised after 2012, at similar discharge levels caused greater damages than there would have been if the protective measures had not been installed. Indeed, in the areas flooded in 2012, destroyed houses were quickly rebuilt (often using the same traditional materials such as banco, an inexpensive consolidated mud)) [36] and even new informal urbanisation zones appeared in the flood zones (Saguia). Therefore, a new approach is required to lower the flood damages, based 
on relocating the more exposed items and providing generally more space in the river system as defined by the European Flood Directive 2007/60/EC [69].

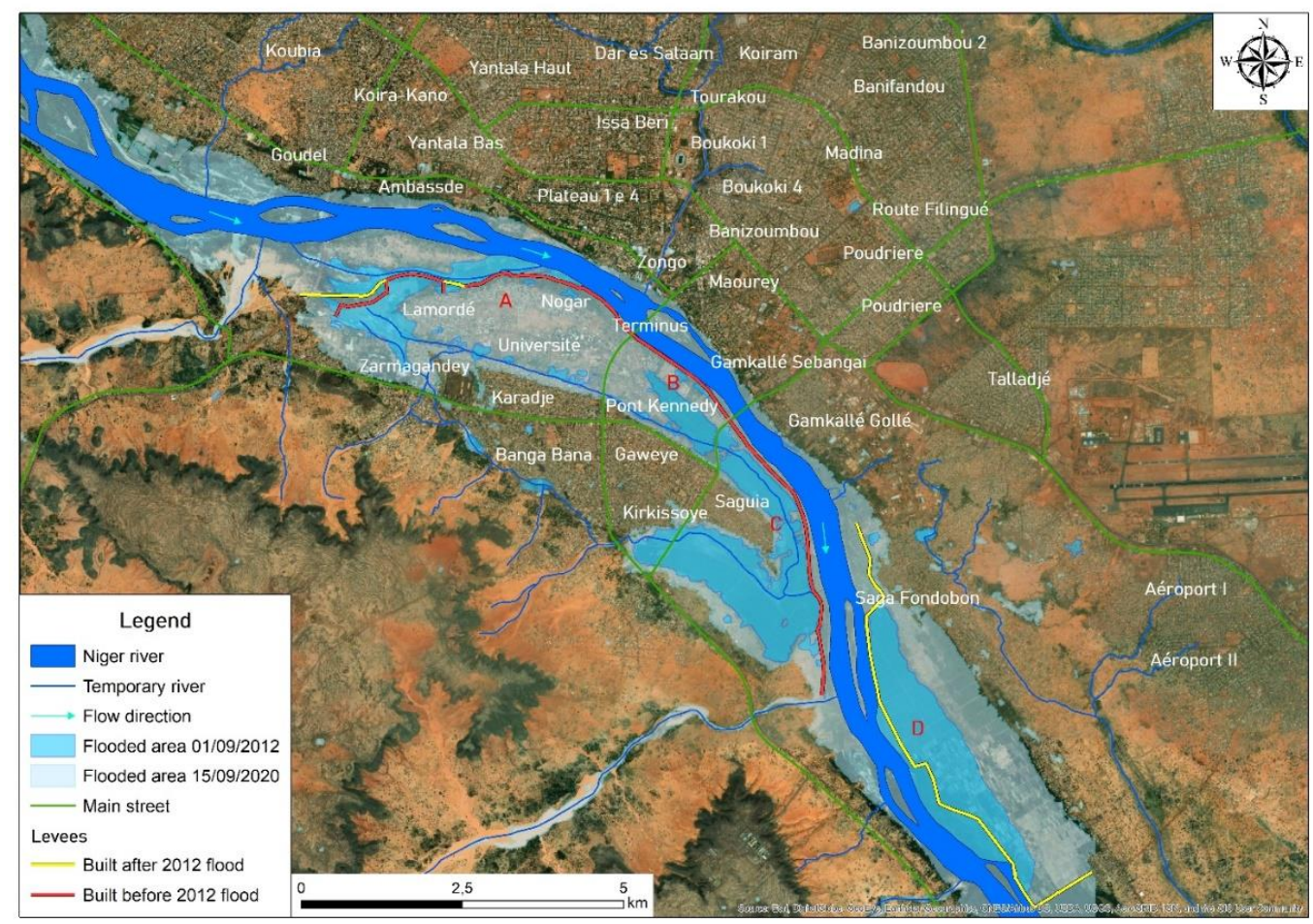

Figure 19. Comparison of Niamey flooded areas in 2012 and 2020 events. The red letters identify the four levee sectors: (A) Lamordé, (B) bridges, (C) Kirkissoye-Saguia and (D) Saga.

\section{Conclusions}

Niamey Capital city is extremely exposed to floods, as demonstrated by recorded damages during the last decade and the urban expansion rate in floodplains. The study demonstrates that the MNRB is now in a new hydroclimatic era characterised by continuously rising hydrological parameters converging with as much rising precipitation amounts and frequency of extremes. This pattern reflects the trends of RCs of Sahelian tributaries, which are reaching a plateau, suggesting a forthcoming end of the Sahelian paradox in the MNRB.

This configuration increases the causal effect of climatic extremes on hydrological ones. Even if underlying causes of hydrological changes in the long term are both anthropogenic and climatic, during the last decade the latter overtook the first in MNRB. The consequence is that Niamey was flooded with an extremely high frequency in the last decade (Table 6). Non-stationary RP analysis was fundamental to evaluating the current expected probability in a context of hydrological changes and different behaviour between black and red flood peaks. The observations show, not only with statistical indices but also with ground effects, that the hazard thresholds exceed too frequently for a large city like Niamey and this leaves many questions open. Could such a level of risk be acceptable? What are the most appropriate measures to reduce it? An actualised and comprehensive flood-risk assessment is therefore needed and should consider:

- Changes in river morphology (including levees) that affect the hydrometric rating curve;

- Recorded damages during the last flood events;

- The updated frequency of extreme events and the potential (and predictable) hydroclimatic changes.

The latter demand further research on: 
- Updated hydrology responses to hydrological changes (intensity and frequency of extreme events) including the non-stationarity of exceedance probability;

- The balance of solid transportation of the river;

- Analysis of river expansion areas (natural and artificial);

- Numerical hydraulic simulations that will simulate the river behaviour according to the hydrographs of the observed flood events and detailed flood-prone area scenarios according to more appropriate hazard thresholds.

On these bases, authorities can define the acceptable flood-risk level and therefore decide the approach for flood-risk reduction. In the past, most resources were invested in protection measures. However, the observed dynamics of water levels in flood periods raise the need for using the NS analysis in hydraulic infrastructures design. The Niamey hazard thresholds are coherent with the actual levees' extent and elevation but, considering the expected probability of threshold surpassing ( $R P=39$ years; NS-RP $=4.2$ years), these protection measures are insufficient. Despite the recent expansion of the levee system no modelling study has yet assessed their implications for high floodwater regimes and the distribution of floodwaters and changes therein in a framework of rapidly expanding urbanisation in floodplains on the right bank. Moreover, levees alone proved to be ineffective in a context of low investments for maintenance and repairing, while dredging of the riverbed is hardly feasible and very expensive without upstream erosion control measures or hydraulic structures to benefit depositing. A large set of no-regret strategies for water and soil conservation exists to limit the runoff and enhance infiltration within tributary river basins by re-vegetation, sustainable cropping and herding practices, but their largescale application over Sahelian basins is far from being widespread. Moreover, further research is needed to understand at river basin scale the behaviour of underlying factors of hydrological changes during the last period. For this purpose, recent methodologies developed at small sub-basin or plot level $[70,71]$ could be successfully integrated with large-scale remote sensing and spatial analysis approaches [23].

Finally, increasing flood frequency and magnitude calls for further research to improve the Flood Early Warning System in MNRB and particularly Niamey capital city. Indeed, despite the recent improvements of hydrological forecasting systems (such as GloFAS, Hype, SATH), they are not able to properly forecast water levels of the Sahelian flood $[72,73]$ and the water levels in Niamey are not related to flood-risk scenarios [13]. Therefore, there is the need for a calibration of forecasts to local conditions and for integrating them into a comprehensive community and impact-based early warning system built on the four pillars identified by the United Nations International Strategy for Disasters Reduction [74]. The development of such a system has recently been successfully tested in Niger on the Sirba River [35], an example that could be usefully applied also in Niamey.

Supplementary Materials: The following are available online at https:/ / www.mdpi.com/article/10 $.3390 / w 13121659 /$ s1, Table S1 Results of the statistical tests for Hubert Segmentation of AMAX at Niamey and Rainfall over MNRB.

Author Contributions: G.M.: methodology, analysis and elaboration of hydrological and topographic data, writing original draft; M.B.: methodology, analysis and elaboration of climatic data, writing original draft; L.D.: methodology, writing—review and editing, supervision; M.H.I.: flow measurements and rating curve analysis, writing-review and editing, supervision; E.F.: analysis and elaboration of flooded areas, writing-review and editing; G.L.K.: writing review; G.P.: analysis and elaboration of hydrological non-stationary return periods, writing-review and editing; A.P.: writing-review and editing, supervision; M.R.: writing-review and editing, supervision; E.S.: analysis and elaboration of hydrological non-stationary return periods; A.T.: analysis and elaboration of hydrological and topographic data; T.D.F.: writing - review and editing; L.R.: hydrological data base management, writing-review and editing; S.B.: statistical analysis of data series and editing; M.T.: analysis of urban dynamics, writing — review and editing; T.V.: analysis and elaboration of hydrological non-stationary return periods, writing - review and editing; V.T.: coordination, methodology, writing original draft, funding acquisition, supervision. All authors have read and agreed to the published version of the manuscript. 
Funding: This research was funded by the Agenzia Italiana per la Cooperazione allo Sviluppo, with an in-kind co-funding by the Istituto per la Bioeconomia (IBE)-Consiglio Nazionale delle Ricerche of Italy (CNR), the Direction de la Météorologie Nationale of Niger (DMN), and by DIST Politecnico and Università di Torino within the project ANADIA2.0 (Aid10848).

Institutional Review Board Statement: Not applicable.

Informed Consent Statement: Not applicable.

Data Availability Statement: Data are available on demand.

Acknowledgments: We would like to thank Abdoul Aziz Kountché (Drone Africa Service) for aerial images and topographical data.

Conflicts of Interest: The authors declare no conflict of interest. The funders had no role in the design of the study; in the collection, analyses or interpretation of data; in the writing of the document, or in the decision to publish the results.

\section{Appendix A}

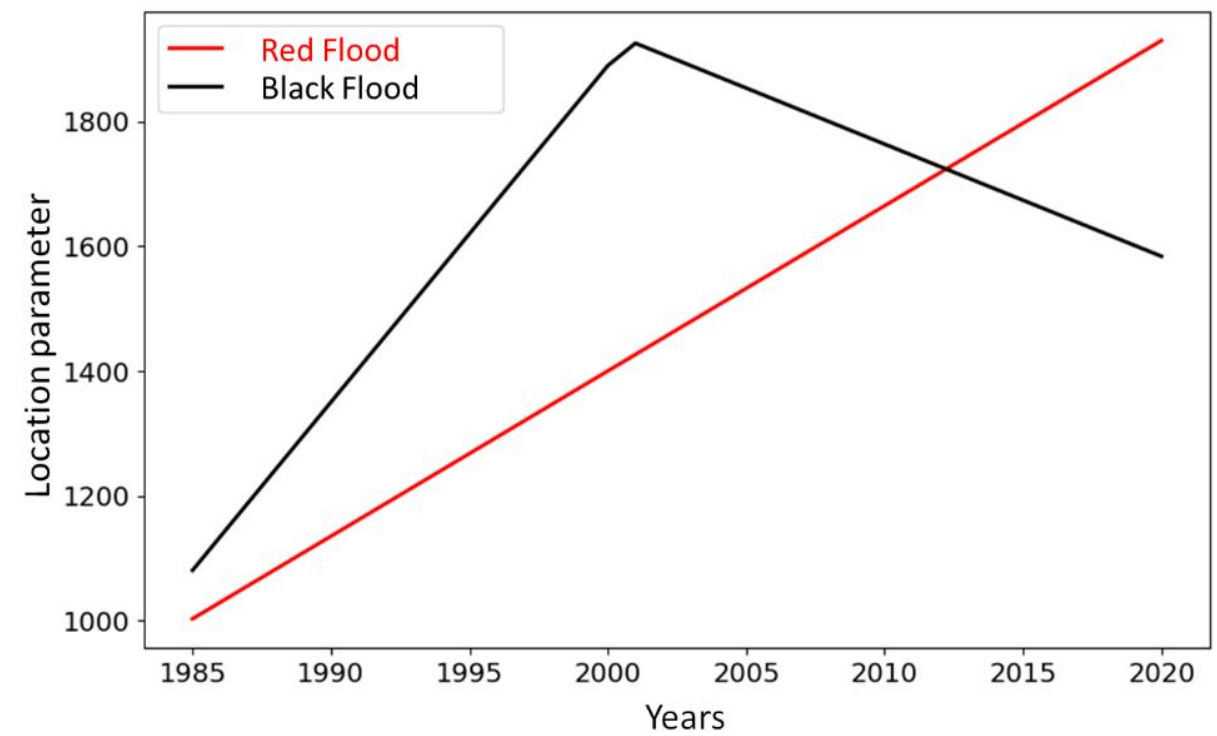

Figure A1. Evolution over time of the GEV location parameter giving the best fitting results to the AMAX series of the red and black floods.

Table A1. Results of the regression of AMIN (h) with Time and Rainfall over the Niger river Basin at Niamey (Robust standard errors in parentheses ${ }^{* *} p<0.01,{ }^{* *} p<0.05,{ }^{*} p<0.1$ ).

\begin{tabular}{ccc}
\hline & $\mathbf{( 1 )}$ & $\mathbf{( 1 )}$ \\
\hline VARIABLES & AMIN (h) & AMIN (h) \\
\hline Time & $2.636^{* * * *}$ & $1.934^{* * *}$ \\
& $(0.407)$ & $(0.339)$ \\
Rainfall & & $0.196^{* * *}$ \\
& & $(0.039)$ \\
Constant & $-5162.844^{* * *}$ & $-3889.949^{* * *}$ \\
& $(817.338)$ & $(671.527)$ \\
Observations & 36 & 36 \\
R-squared & 0.56 & 0.700 \\
\hline
\end{tabular}




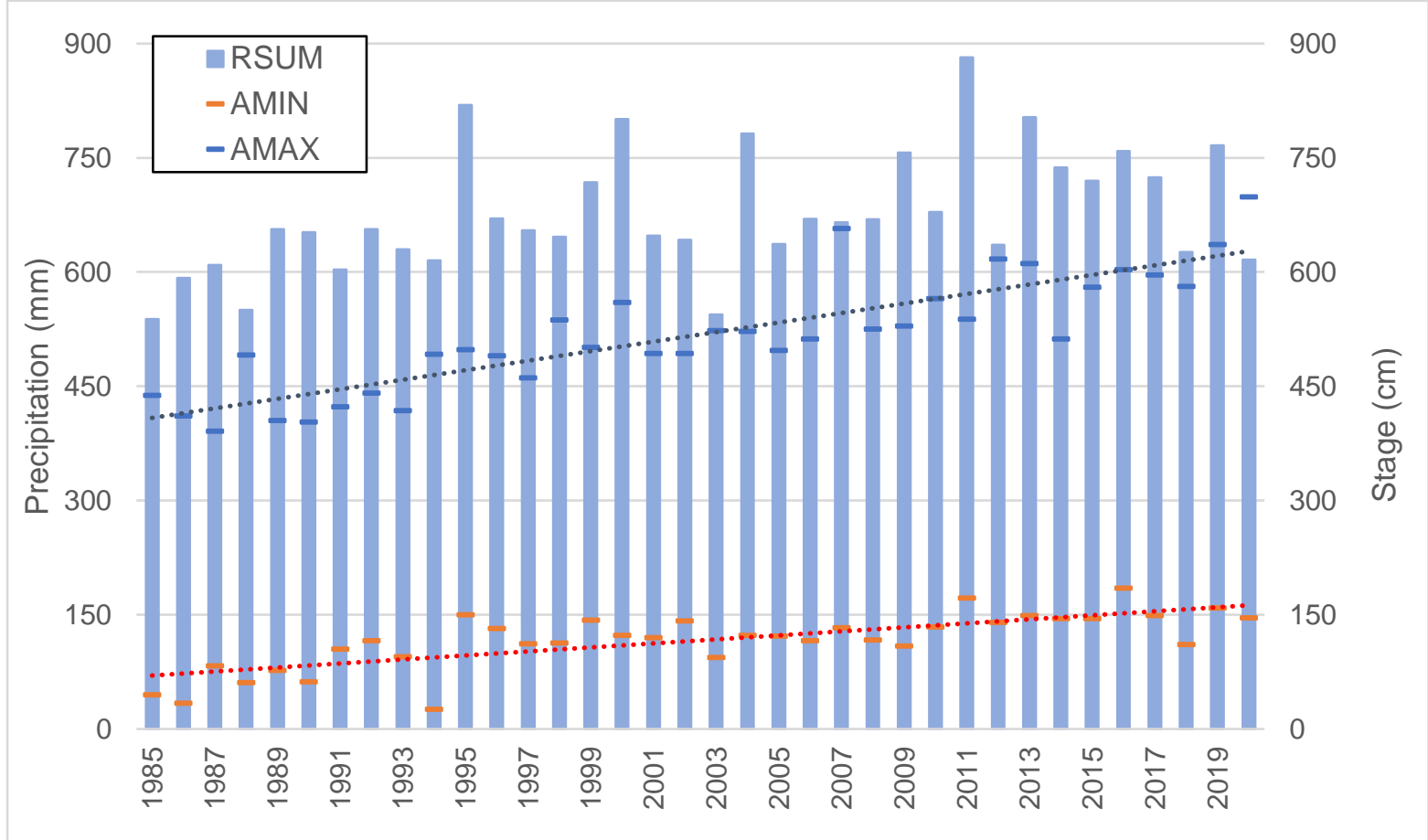

Figure A2. Trends of AMAX (h), AMIN (h) and annual precipitation (RSUM) over the whole Niger River Basin (1985-2020).

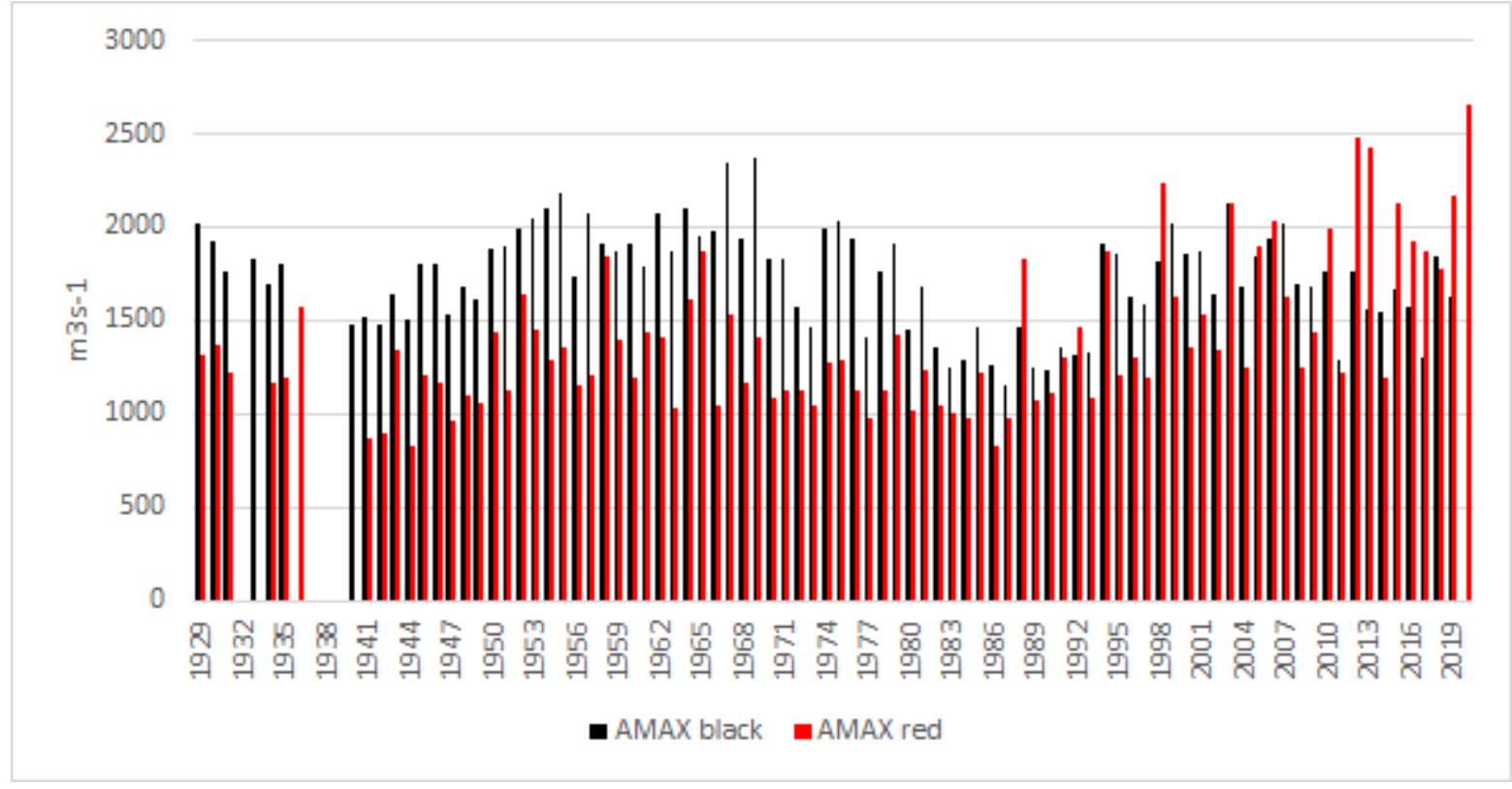

Figure A3. AMAX of the red and black flood at Niamey gauging station. 
Table A2. Results of the regression of AMAX $(Q)$ with time and rainfall over the Niger river Basin at Niamey (standard errors in parentheses ${ }^{* * *} p<0.01,{ }^{* *} p<0.05,{ }^{*} p<0.1$ ).

\begin{tabular}{ccc}
\hline & $\mathbf{( 1 )}$ & $\mathbf{( 1 )}$ \\
\hline VARIABLES & AMAX(Q) & AMAX(Q) \\
\hline Time & $12.141^{* * *}$ & $12.589^{* * *}$ \\
& $(2.554)$ & $(1.699)$ \\
Rainfall & & $3.475^{* * *}$ \\
& & $(0.393)$ \\
Constant & $-22,691.601^{* * *}$ & $-25,162.330^{* * *}$ \\
& $(5079.87)$ & $(3388.772)$ \\
Observations & 63 & 63 \\
R-squared & 0.27 & 0.683 \\
\hline
\end{tabular}

Table A3. Data series segmentation (Hubert with Scheffé test 0.01) of red AMAX at Niamey and annual precipitation over MNRB.

\begin{tabular}{ccccccc}
\hline MNRB Annual Rainfall & & $\mathbf{1 9 5 8 - 1 9 6 7}$ & $\mathbf{1 9 6 8 - 1 9 8 2}$ & $\mathbf{1 9 8 3 - 1 9 8 7}$ & $\mathbf{1 9 8 8 - 2 0 1 1}$ & $\mathbf{2 0 1 2 - 2 0 2 0}$ \\
\hline Av \pm st.dev $(\mathrm{mm})$ & & $547 \pm 45$ & $424 \pm 39$ & $313 \pm 27$ & $440 \pm 63$ & $518 \pm 44$ \\
\hline Nim AMAX red & $\mathbf{1 9 2 9 - 1 9 4 0}$ & & $\mathbf{1 9 4 1 - 1 9 9 7}$ & & $\mathbf{1 9 9 8 - 2 0 1 1}$ & $\mathbf{2 0 1 2 - 2 0 2 0}$ \\
\hline Av \pm st.dev $\left(\mathrm{m}^{3} / \mathrm{s}\right)$ & $1306 \pm 150$ & & $1235 \pm 253$ & & $1639 \pm 355$ & $2068 \pm 442$ \\
\hline
\end{tabular}


Table A4. Rainfall indexes over the MNRB.

\begin{tabular}{|c|c|c|c|c|c|c|c|c|c|c|c|c|}
\hline Year & RSUM & RR1 & SDII & N_Days_95C & N_Days_95C_July & N_Days_95C_August & N_Days_95C_Sept. & Rain_95C & Contrib_95C & MAX1 & MAX5 & ARI \\
\hline 1981 & 406.3 & 50.8 & 7.9 & 3.8 & 1.4 & 1.3 & 0.7 & 135.1 & 0.32 & 46.6 & 69.2 & -0.29 \\
\hline 1982 & 352.6 & 42.3 & 8.3 & 2.5 & 0.4 & 1.7 & 0.3 & 70.6 & 0.21 & 32.5 & 51.4 & -0.92 \\
\hline 1983 & 329.6 & 42.3 & 7.6 & 1.7 & 0.5 & 1.0 & 0.1 & 45.0 & 0.15 & 26.5 & 51.7 & -1.24 \\
\hline 1985 & 335.1 & 41.1 & 8.0 & 1.6 & 0.4 & 1.0 & 0.2 & 45.9 & 0.12 & 26.5 & 47.9 & -1.19 \\
\hline 1986 & 344.7 & 43.0 & 7.9 & 1.5 & 0.4 & 0.8 & 0.1 & 40.7 & 0.11 & 26.1 & 48.1 & -1.00 \\
\hline 1987 & 309.0 & 43.0 & 7.0 & 1.1 & 0.2 & 0.3 & 0.4 & 33.3 & 0.08 & 24.1 & 37.8 & -1.50 \\
\hline 1988 & 451.4 & 50.1 & 8.9 & 3.8 & 0.5 & 2.7 & 0.1 & 109.4 & 0.25 & 34.6 & 68.8 & 0.32 \\
\hline 1990 & 350.5 & 44.8 & 7.6 & 0.9 & 0.4 & 0.5 & 0.0 & 24.8 & 0.06 & 23.5 & 47.4 & -0.94 \\
\hline 1991 & 448.8 & 49.8 & 8.9 & 2.3 & 0.7 & 1.5 & 0.0 & 64.7 & 0.13 & 28.6 & 57.9 & 0.29 \\
\hline 1992 & 402.0 & 47.7 & 8.2 & 2.3 & 0.5 & 1.8 & 0.0 & 62.5 & 0.15 & 28.8 & 56.4 & -0.33 \\
\hline 1993 & 365.6 & 45.0 & 7.9 & 1.4 & 0.8 & 0.6 & 0.0 & 37.2 & 0.10 & 26.1 & 48.5 & -0.74 \\
\hline 1994 & 540.8 & 59.5 & 8.9 & 3.6 & 0.6 & 2.6 & 0.5 & 101.7 & 0.18 & 33.0 & 62.6 & 1.42 \\
\hline 1995 & 411.0 & 51.8 & 7.8 & 2.5 & 0.3 & 2.0 & 0.1 & 68.1 & 0.15 & 28.7 & 55.2 & -0.19 \\
\hline 1996 & 379.4 & 47.7 & 7.8 & 1.1 & 0.3 & 0.5 & 0.2 & 27.4 & 0.07 & 23.6 & 47.1 & -0.61 \\
\hline 1997 & 370.4 & 52.0 & 7.0 & 1.2 & 0.6 & 0.5 & 0.0 & 33.7 & 0.09 & 26.8 & 48.8 & -0.74 \\
\hline 1998 & 505.1 & 54.8 & 9.0 & 3.6 & 1.2 & 1.1 & 1.2 & 101.9 & 0.19 & 31.9 & 61.2 & 1.01 \\
\hline 2000 & 379.1 & 47.3 & 8.0 & 1.7 & 1.2 & 0.5 & 0.0 & 45.1 & 0.12 & 27.5 & 51.3 & -0.54 \\
\hline 2001 & 421.6 & 47.7 & 8.8 & 2.3 & 0.7 & 1.3 & 0.3 & 58.8 & 0.15 & 28.6 & 46.9 & 0.03 \\
\hline 2002 & 420.3 & 48.6 & 8.5 & 2.3 & 0.8 & 1.2 & 0.2 & 58.0 & 0.15 & 27.8 & 50.9 & -0.03 \\
\hline 2003 & 527.3 & 57.8 & 8.8 & 3.1 & 1.0 & 1.3 & 0.5 & 84.7 & 0.15 & 29.4 & 56.1 & 1.19 \\
\hline 2004 & 365.4 & 43.9 & 8.1 & 1.9 & 0.8 & 0.9 & 0.2 & 47.9 & 0.13 & 25.7 & 45.0 & -0.73 \\
\hline 2005 & 501.1 & 54.6 & 9.0 & 3.5 & 0.9 & 1.3 & 0.6 & 93.3 & 0.18 & 30.9 & 59.7 & 0.96 \\
\hline 2006 & 389.6 & 47.8 & 8.1 & 1.4 & 0.4 & 1.0 & 0.0 & 35.4 & 0.10 & 25.1 & 50.4 & -0.43 \\
\hline 2007 & 428.1 & 49.6 & 8.5 & 2.5 & 0.6 & 1.6 & 0.3 & 72.2 & 0.16 & 33.5 & 53.6 & 0.05 \\
\hline 2008 & 415.1 & 49.5 & 8.1 & 2.0 & 0.4 & 1.1 & 0.1 & 55.4 & 0.13 & 28.2 & 49.2 & -0.14 \\
\hline 2009 & 424.9 & 52.5 & 7.8 & 1.8 & 0.1 & 1.2 & 0.3 & 51.7 & 0.10 & 26.7 & 56.6 & -0.02 \\
\hline 2010 & 458.9 & 60.1 & 7.5 & 1.6 & 0.6 & 0.6 & 0.4 & 37.9 & 0.09 & 24.6 & 56.2 & 0.47 \\
\hline 2011 & 426.5 & 51.9 & 8.1 & 2.3 & 0.7 & 1.4 & 0.2 & 65.3 & 0.15 & 31.7 & 63.1 & 0.04 \\
\hline 2012 & 544.2 & 57.2 & 9.4 & 4.2 & 0.7 & 2.7 & 0.8 & 111.8 & 0.20 & 32.4 & 70.1 & 1.59 \\
\hline 2013 & 443.5 & 55.1 & 7.9 & 2.7 & 0.4 & 2.3 & 0.0 & 75.2 & 0.16 & 28.8 & 57.3 & 0.26 \\
\hline 2014 & 433.9 & 50.1 & 8.5 & 2.4 & 0.9 & 1.3 & 0.3 & 62.8 & 0.15 & 27.9 & 53.8 & 0.11 \\
\hline
\end{tabular}


Table A4. Cont.

\begin{tabular}{|c|c|c|c|c|c|c|c|c|c|c|c|c|}
\hline Year & RSUM & RR1 & SDII & N_Days_95C & N_Days_95C_July & N_Days_95C_August & N_Days_95C_Sept. & Rain_95C & Contrib_95C & MAX1 & MAX5 & ARI \\
\hline 2015 & 497.2 & 53.6 & 9.1 & 3.6 & 2.1 & 1.3 & 0.1 & 98.7 & 0.19 & 30.0 & 60.4 & 0.90 \\
\hline 2016 & 476.3 & 52.8 & 8.8 & 3.0 & 1.0 & 1.5 & 0.5 & 80.8 & 0.17 & 29.3 & 60.7 & 0.67 \\
\hline 2017 & 450.0 & 47.6 & 9.3 & 3.1 & 0.9 & 1.8 & 0.2 & 80.5 & 0.18 & 28.3 & 52.4 & 0.33 \\
\hline 2018 & 503.0 & 56.2 & 8.9 & 3.3 & 0.8 & 2.0 & 0.5 & 89.0 & 0.18 & 32.3 & 63.3 & 1.04 \\
\hline 2019 & 464.2 & 54.5 & 8.3 & 3.4 & 0.5 & 2.9 & 0.0 & 97.6 & 0.20 & 32.6 & 63.6 & 0.47 \\
\hline 2020 & 563.9 & 55.1 & 10.0 & 5.4 & 0.8 & 3.8 & 0.7 & 157.0 & 0.28 & 38.0 & 74.5 & 1.80 \\
\hline
\end{tabular}




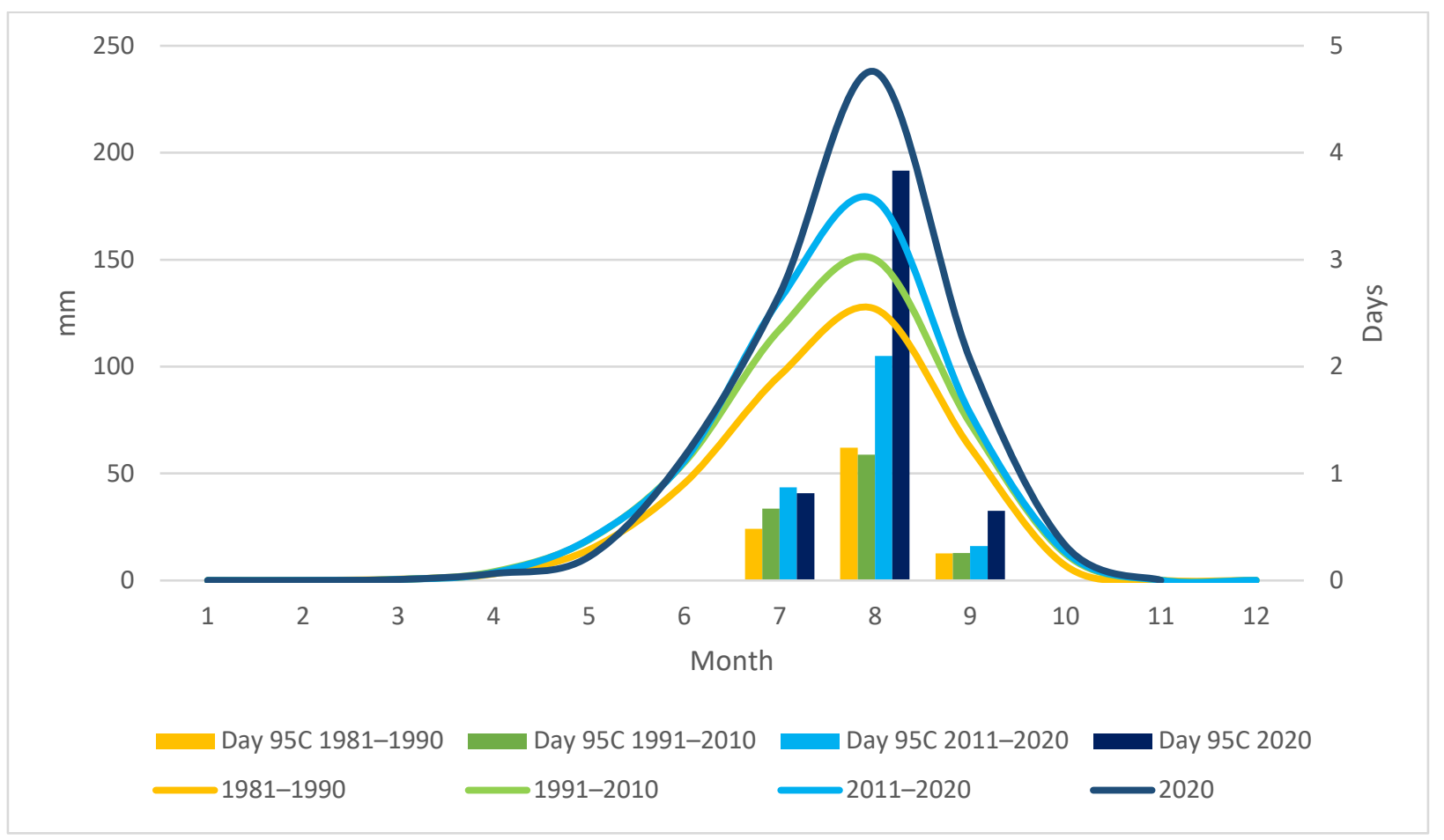

Figure A4. Rainfall distribution during the rainy season over MNRB (Chirps v2) and monthly number of days with precipitation $>95$ th percentile.

Table A5. Anomalies of red AMAX and extreme rainfall indexes for years with red AMAX anomaly <-1 st.dev (sorted by Red AMAX).

\begin{tabular}{|c|c|c|c|c|c|c|c|c|c|c|}
\hline YEAR & $\begin{array}{c}\text { Red } \\
\text { AMAX }\end{array}$ & RSUM & SDII & N_Days_95C & $\begin{array}{c}\text { N_Days_95C } \\
\text { July }\end{array}$ & $\begin{array}{c}\text { N_Days_95C } \\
\text { August }\end{array}$ & $\begin{array}{c}\text { N_Days_95C } \\
\text { Sept. }\end{array}$ & MAX1 & MAX5 & ARI \\
\hline 1986 & -1.54 & -1.17 & -0.64 & -0.99 & -0.79 & -0.78 & -0.83 & -0.76 & -0.93 & -1.14 \\
\hline 1987 & -1.23 & -1.69 & -2.05 & -1.37 & -1.20 & -1.44 & 0.48 & -1.22 & -2.22 & -1.70 \\
\hline 1984 & -1.21 & -2.36 & -1.49 & -0.83 & -1.29 & -1.10 & 0.98 & -0.03 & -1.47 & -2.42 \\
\hline 1983 & -1.15 & -1.39 & -1.11 & -0.75 & -0.35 & -0.51 & -0.79 & -0.65 & -0.48 & -1.40 \\
\hline 1982 & -1.06 & -1.06 & -0.11 & 0.03 & -0.81 & 0.37 & 0.22 & 0.76 & -0.52 & -1.04 \\
\hline
\end{tabular}

\section{References}

1. OCHA. Flooding Situation Report as of 6 November 2020; OCHA: New York, NY, USA, 2020. Available online: https: //www.humanitarianresponse.info/en/operations/west-and-central-africa/infographic/west-and-central-africa-floodingsituation-6-november, (accessed on 3 December 2020).

2. Floodlist. Available online: http:/ / floodlist.com/ (accessed on 3 December 2020).

3. OCHA. Flooding Situation Report as of 25 September 2020; OCHA: New York, NY, USA, 2020. Available online: https: //www.humanitarianresponse.info/en/operations/west-and-central-africa/infographic/west-and-central-africa-floodingsituation-25-september, (accessed on 3 December 2020).

4. Tarhule, A. Damaging Rainfall and Flooding: The Other Sahel Hazards. Clim. Chang. 2005, 72, 355-377. [CrossRef]

5. Nka, B.N.; Oudin, L.; Karambiri, H.; Paturel, J.E.; Ribstein, P. Trends in floods in West Africa: Analysis based on 11 catchments in the region. Hydrol. Earth Syst. Sci. 2015, 19, 4707-4719. [CrossRef]

6. Aich, V.; Koné, B.; Hattermann, F.F.; Paton, E.N. Time Series Analysis of Floods across the Niger River Basin. Water 2016, 8, 165. [CrossRef]

7. Fiorillo, E.; Crisci, A.; Issa, H.; Maracchi, G.; Morabito, M.; Tarchiani, V. Recent Changes of Floods and Related Impacts in Niger Based on the ANADIA Niger Flood Database. Climate 2018, 6, 59. [CrossRef]

8. Descroix, L.; Mahé, G.; Lebel, T.; Favreau, G.; Galle, S.; Gautier, E.; Olivry, J.-C.; Albergel, J.; Amogu, O.; Cappelaere, B.; et al. Spatio-temporal variability of hydrological regimes around the boundaries between Sahelian and Sudanian areas of West Africa: A synthesis. J. Hydrol. 2009, 375, 90-102. [CrossRef] 
9. Amogu, O.; Descroix, L.; Yéro, K.S.; Le Breton, É.; Mamadou, I.; Ali, A.; Vischel, T.; Bader, J.-C.; Moussa, I.B.; Gautier, E.; et al. Increasing River Flows in the Sahel? Water 2010, 2, 170-199. [CrossRef]

10. Descroix, L.; Genthon, P.; Amogu, O.; Rajot, J.-L.; Sighomnou, D.; Vauclin, M. Change in Sahelian Rivers hydrograph: The case of recent red floods of the Niger River in the Niamey region. Glob. Planet. Chang. 2012, 98-99, 18-30. [CrossRef]

11. Descroix, L. Processus Et Enjeux D'eau En Afrique De l'Ouest Soudano-Sahélienne; Editions des Archives Contemporaines: Paris, France, 2018. [CrossRef]

12. Wilcox, C.; Vischel, T.; Panthou, G.; Bodian, A.; Blanchet, J.; Descroix, L.; Quantin, G.; Cassé, C.; Tanimoun, B.; Kone, S. Trends in hydrological extremes in the Senegal and Niger Rivers. J. Hydrol. 2018, 566, 531-545. [CrossRef]

13. Massazza, G.; Tamagnone, P.; Wilcox, C.; Belcore, E.; Pezzoli, A.; Vischel, T.; Panthou, G.; Ibrahim, M.H.; Tiepolo, M.; Tarchiani, V.; et al. Flood Hazard Scenarios of the Sirba River (Niger): Evaluation of the Hazard Thresholds and Flooding Areas. Water 2019, 11, 1018. [CrossRef]

14. Descroix, L.; Bouzou, I.; Genthon, P.; Sighomnou, D.; Mahé, G.; Mamadou, I.; Vandervaere, J.-P.; Gautier, E.; Faran, O.; Rajot, J.L.; et al. Impact of Drought and Land - Use Changes on Surface-Water Quality and Quantity: The Sahelian Paradox. In Current Perspectives in Contaminant Hydrology and Water Resources Sustainability; IntechOpen: London, UK, 2013.

15. Descroix, L.; Guichard, F.; Grippa, M.; Lambert, L.A.; Panthou, G.; Mahé, G.; Gal, L.; Dardel, C.; Quantin, G.; Kergoat, L.; et al. Evolution of Surface Hydrology in the Sahelo-Sudanian Strip: An Updated Review. Water 2018, 10, 748. [CrossRef]

16. Herrmann, S.M.; Anyamba, A.; Tucker, C.J. Recent trends in vegetation dynamics in the African Sahel and their relationship to climate. Glob. Environ. Chang. 2005, 15, 394-404. [CrossRef]

17. Dardel, C.; Kergoat, L.; Hiernaux, P.; Grippa, M.; Mougin, E.; Ciais, P.; Nguyen, C.-C. Rain-Use-Efficiency: What it Tells us about the Conflicting Sahel Greening and Sahelian Paradox. Remote. Sens. 2014, 6, 3446-3474. [CrossRef]

18. Mahe, G.; Paturel, J.-E.; Servat, E.; Conway, D.; Dezetter, A. The impact of land use change on soil water holding capacity and river flow modelling in the Nakambe River, Burkina-Faso. J. Hydrol. 2005, 300, 33-43. [CrossRef]

19. Leblanc, M.; Favreau, G.; Massuel, S.; Tweed, S.O.; Loireau, M.; Cappelaere, B. Land clearance and hydrological change in the Sahel: SW Niger. Glob. Planet. Chang. 2008, 61, 135-150. [CrossRef]

20. Trichon, V.; Hiernaux, P.; Walcker, R.; Mougin, E. The persistent decline of patterned woody vegetation: The tiger bush in the context of the regional Sahel greening trend. Glob. Chang. Biol. 2018, 24, 2633-2648. [CrossRef]

21. Casse, C.; Gosset, M.; Vischel, T.; Quantin, G.; Tanimoun, B.A. Model-based study of the role of rainfall and land use-land cover in the changes in the occurrence and intensity of Niger red floods in Niamey between 1953 and 2012. Hydrol. Earth Syst. Sci. 2016, 20, 2841-2859. [CrossRef]

22. Panthou, G.; Lebel, T.; Vischel, T.; Quantin, G.; Sane, Y.; Ba, A.; Ndiaye, O.; Diongue-Niang, A.; Diopkane, M. Rainfall intensification in tropical semi-arid regions: The Sahelian case. Environ. Res. Lett. 2018, 13, 064013. [CrossRef]

23. Brandt, M.; Hiernaux, P.; Rasmussen, K.; Tucker, C.J.; Wigneron, J.-P.; Diouf, A.A.; Herrmann, S.M.; Zhang, W.; Kergoat, L.; Mbow, C.; et al. Changes in rainfall distribution promote woody foliage production in the Sahel. Commun. Biol. 2019, 2, 1-10. [CrossRef] [PubMed]

24. Mamadou, I.; Gautier, E.; Descroix, L.; Noma, I.; Moussa, I.B.; Maiga, O.F.; Genthon, P.; Amogu, O.; Abdou, M.M.; Vandervaere, J.-P. Exorheism growth as an explanation of increasing flooding in the Sahel. Catena 2015, 131, 130-139. [CrossRef]

25. Amogu, O. Sahelian Land-Cover Degradation and Its Effects on the Silting-Up of the Middle Niger River. Hydrology. Universite Joseph-Fourier-Grenoble I. 2009. Available online: https: / tel.archives-ouvertes.fr/tel-00385629 (accessed on 10 December 2020).

26. Tamagnone, P.; Massazza, G.; Pezzoli, A.; Rosso, M. Hydrology of the Sirba River: Updating and Analysis of Discharge Time Series. Water 2019, 11, 156. [CrossRef]

27. Bechler-Carmaux, N.; Mietton, M.; LaMotte, M. Le risque d'inondation fluviale à Niamey (Niger). Aléa, vulnérabilité et cartographie/ / River flood risks in Niamey (Niger). Hazards, vulnerability and mapping. Ann. Géographie 2000, 109, 176-187. [CrossRef]

28. Abdou Alou, A. La Ville de Niamey Face aux Inondations Fluviales. Vulnérabilité et Résilience des Modes d'Adaptation Individuels et Collectifs. Géographie. Université de Niamey, 2018, HAL Id: Tel-01945249. Available online: https: / / tel.archivesouvertes.fr/tel-01945249 (accessed on 10 December 2020).

29. Issaka, I.; Badariotti, D. Les inondations à Niamey, enjeux autour d'un phénomène complexe. Cah. d'Outre-Mer 2013, 263, 295-310. [CrossRef]

30. BDNIA. Available online: www.inondations-niger.org. (accessed on 13 December 2020).

31. Amani, A.; Paturel, J.-E. Le projet de révision des normes hydrologiques en Afrique de l'Ouest et Afrique Centrale. Météorologie 2017, 6-7. [CrossRef]

32. Fiorillo, E.; Maselli, F.; Tarchiani, V.; Vignaroli, P. Analysis of land degradation processes on a tiger bush plateau in South West Niger using MODIS and LANDSAT TM/ETM+ data. Int. J. Appl. Earth Obs. Geoinf. 2017, 62, 56-68. [CrossRef]

33. Tarhule, A.; Zume, J.T.; Grijsen, J.; Talbi-Jordan, A.; Guero, A.; Dessouassi, R.Y.; Doffou, H.; Kone, S.; Coulibaly, B.; Harshadeep, N.R.; et al. Exploring temporal hydroclimatic variability in the Niger Basin (1901-2006) using observed and gridded data. Int. J. Clim. 2014, 35, 520-539. [CrossRef]

34. AMMA-CATCH. Available online: http:/ / www.amma-catch.org/ (accessed on 19 January 2021). 
35. Tarchiani, V.; Massazza, G.; Rosso, M.; Tiepolo, M.; Pezzoli, A.; Ibrahim, M.H.; Katiellou, G.L.; Tamagnone, P.; De Filippis, T.; Rocchi, L.; et al. Community and Impact Based Early Warning System for Flood Risk Preparedness: The Experience of the Sirba River in Niger. Sustainability 2020, 12, 1802. [CrossRef]

36. Tiepolo, M.; Tarchiani, V. Risque et Adaptation Climatique Dans la Région Tillabéri, Niger; L'Harmattan: Paris, France, 2016; ISBN 978-2-343-08493-0.

37. Sai, F.; Cumiskey, L.; Weerts, A.; Bhattacharya, B.; Haque Khan, R. Towards impact-based flood forecasting and warning in Bangladesh: A case study at the local level in Sirajganj district. Nat. Hazards Earth Syst. Sci. Discuss. 2018, $2018,1-20$.

38. Lehner, B.; Verdin, K.; Jarvis, A. New Global Hydrography Derived from Spaceborne Elevation Data. Eos 2008, 89, 93-94. [CrossRef]

39. Lehner, B.; Grill, G. Global river hydrography and network routing: Baseline data and new approaches to study the world's large river systems. Hydrol. Process. 2013, 27, 2171-2186. [CrossRef]

40. Andersson, J.C.; Ali, A.; Arheimer, B.; Gustafsson, D.; Minoungou, B. Providing peak river flow statistics and forecasting in the Niger River basin. Phys. Chem. Earth Parts A/B/C 2017, 100, 3-12. [CrossRef]

41. Herschy, R.W. Streamflow Measurement; Chapman \& Hall: London, UK, 1995.

42. Shiau, J.T. Return period of bivariate distributed extreme hydrological events. Stoch. Environ. Res. Risk Assess. 2003, 17, 42-57. [CrossRef]

43. Galligari, A.; Tonolo, F.G.; Massazza, G. Floodplain Settlement Dynamics in the Maouri Dallol at Guéchémé, Niger: A Multidisciplinary Approach. Sustainability 2020, 12, 5632. [CrossRef]

44. Thas, O.; Ottoy, J. Some generalizations of the Anderson-Darling statistic. Stat. Probab. Lett. 2003, 64, 255-261. [CrossRef]

45. Dembélé, M.; Zwart, S.J. Evaluation and comparison of satellite-based rainfall products in Burkina Faso, West Africa. Int. J. Remote. Sens. 2016, 37, 3995-4014. [CrossRef]

46. Poméon, T.; Jackisch, D.; Diekkrüger, B. Evaluating the performance of remotely sensed and reanalysed precipitation data over West Africa using HBV light. J. Hydrol. 2017, 547, 222-235. [CrossRef]

47. Bichet, A.; Diedhiou, A. West African Sahel has become wetter during the last 30 years, but dry spells are shorter and more frequent. Clim. Res. 2018, 75, 155-162. [CrossRef]

48. Funk, C.; Peterson, P.; Landsfeld, M.; Pedreros, D.; Verdin, J.; Shukla, S.; Husak, G.; Rowland, J.; Harrison, L.; Hoell, A.; et al. The climate hazards infrared precipitation with stations-a new environmental record for monitoring extremes. Sci. Data 2015, 2, 150066. [CrossRef]

49. Usman, M.; Nichol, J.E.; Ibrahim, A.T.; Buba, L.F. A spatio-temporal analysis of trends in rainfall from long term satellite rainfall products in the Sudano Sahelian zone of Nigeria. Agric. For. Meteorol. 2018, 260-261, 273-286. [CrossRef]

50. Abatzoglou, J.T.; Dobrowski, S.Z.; Parks, S.A.; Hegewisch, K.C. TerraClimate, a high-resolution global dataset of monthly climate and climatic water balance from 1958-2015. Sci. Data 2018, 5, 170191. [CrossRef]

51. Muthoni, F.K. Spatial-Temporal Trends of Rainfall, Maximum and Minimum Temperatures Over West Africa. IEEE J. Sel. Top. Appl. Earth Obs. Remote. Sens. 2020, 13, 2960-2973. [CrossRef]

52. Zhang, X.; Alexander, L.; Hegerl, G.; Jones, P.; Tank, A.K.; Peterson, T.C.; Trewin, B.; Zwiers, F.W. Indices for monitoring changes in extremes based on daily temperature and precipitation data. Wiley Interdiscip. Rev. Clim. Chang. 2011, 2, 851-870. [CrossRef]

53. L'Hôte, Y.; Mahé, G.; Somé, B.; Triboulet, J.P. Analysis of a Sahelian annual rainfall index from 1896 to 2000; the drought continues. Hydrol. Sci. J. 2002, 47, 563-572. [CrossRef]

54. Mays, L.W. Water Resources Engineering; Wiley: Hoboken, NJ, USA, 2010; ISBN 978-0-470-46064-1.

55. Hubert, P.; Carbonnel, J.P.; Chaouche, A.J. Segmentation des séries hydrométéorologiques-Application à des séries de précipitations et de débits de l'afrique de l'ouest. J. Hydrol. 1989, 110, 349-367. [CrossRef]

56. Conroy, R.M. What hypotheses do "nonparametric" two-group tests actually test? Stata J. 2012, 12, 182-190. [CrossRef]

57. Drone Africa Service. Available online: www.drone-africa-service.com (accessed on 12 December 2020).

58. Boschetti, M.; Nutini, F.; Manfron, G.; Brivio, P.A.; Nelson, A. Comparative Analysis of Normalised Difference Spectral Indices Derived from MODIS for Detecting Surface Water in Flooded Rice Cropping Systems. PLoS ONE 2014, 9, e88741. [CrossRef] [PubMed]

59. Tiepolo, M.; Braccio, S. 13. Flood Risk Assessment at Municipal Level in the Tillabéri Region, Niger. In Planning to Cope with Tropical and Subtropical Climate Change; Walter de Gruyter: Warsaw, Poland, 2016; pp. 221-242.

60. Aich, V.; Liersch, S.; Vetter, T.; Andersson, J.C.M.; Mueller, E.N.; Hattermann, F.F. Climate or Land Use?-Attribution of Changes in River Flooding in the Sahel Zone. Water 2015, 7, 2796-2820. [CrossRef]

61. Lebel, T.; Panthou, G.; Vischel, T. Inondations en Afrique: Une Nouvelle ère Hydroclimatique. The Conversation. 2020. Available online: https:/ / theconversation.com/inondations-en-afrique-une-nouvelle-ere-hydroclimatique-148739 (accessed on 3 December 2020).

62. Barnieh, B.A.; Jia, L.; Menenti, M.; Zhou, J.; Zeng, Y. Mapping Land Use Land Cover Transitions at Different Spatiotemporal Scales in West Africa. Sustain. 2020, 12, 8565. [CrossRef]

63. Brandt, M.; Wigneron, J.-P.; Chave, J.; Tagesson, T.; Penuelas, J.; Ciais, P.; Rasmussen, K.; Tian, F.; Mbow, C.; Al-Yaari, A.; et al. Satellite passive microwaves reveal recent climate-induced carbon losses in African drylands. Nat. Ecol. Evol. 2018, 2, 827-835. [CrossRef] 
64. Mounirou, L.A.; Zouré, C.O.; Yonaba, R.; Paturel, J.-E.; Mahé, G.; Niang, D.; Yacouba, H.; Karambiri, H. Multi-scale analysis of runoff from a statistical perspective in a small Sahelian catchment under semi-arid climate. Arab. J. Geosci. 2020, $13,1-16$. [CrossRef]

65. Mamadou, I. La Dynamique des Koris et l'Ensablement de Leur Iit et de Celui du Fleuve Niger dans la Région de Niamey. Ph.D. Thesis, Paris 1 Panthéon Sorbonne University, Paris, France, Abdou Moumouni University of Niamey, Niamey, Niger, $2012 ;$ p. 260. Available online: https://www.researchgate.net/publication/316989625_LA_DYNAMIQUE_ACCELEREE_DES_KORIS_DE_ LA_REGION_DE_NIAMEY_ET_SES_CONSEQUENCES_SUR_L \T1 \textquoterightENSABLEMENT_DU_FLEUVE_NIGER (accessed on 28 January 2021).

66. Heine, R.A.; Pinter, N. Levee effects upon flood levels: An empirical assessment. Hydrol. Process. 2012, 26, 3225-3240. [CrossRef]

67. Di Baldassarre, G.; Viglione, A.; Carr, G.; Kuil, L.; Yan, K.; Brandimarte, L.; Bloschl, G. Debates-Perspectives on socio-hydrology: Capturing feedbacks between physical and social processes. Water Resour. Res. 2015, 51, 4770-4781. [CrossRef]

68. Housseini, I.M. Scénarios de Comportement des Digues de Protection Face au Risque d'Inondation Fluviale; Technical Note; Directorate General of Water Ressources: Niamey, Niger, 2020.

69. Smith, R. Directive 2008/94/EC of the European Parliament and of the Council of 22 October 2008; Official Journal of the European Union: Bruxelles, Belgium, 2007; pp. 423-426.

70. Yonaba, R.; Biaou, A.C.; Koïta, M.; Tazen, F.; Mounirou, L.A.; Zouré, C.O.; Queloz, P.; Karambiri, H.; Yacouba, H. A dynamic land use/land cover input helps in picturing the Sahelian paradox: Assessing variability and attribution of changes in surface runoff in a Sahelian watershed. Sci. Total. Environ. 2021, 757, 143792. [CrossRef]

71. Marega, O.; Emeterio, J.-L.S.; Fall, A.; Andrieu, J. Cartographie par télédétection des variations spatio-temporelles de la couverture végétale spontanée face à la variabilité pluviométrique au Sahel: Approche multiscalaire. Physio-Géo 2021, 16, 1-28. [CrossRef]

72. Passerotti, G.; Massazza, G.; Pezzoli, A.; Bigi, V.; Zsótér, E.; Rosso, M. Hydrological Model Application in the Sirba River: Early Warning System and GloFAS Improvements. Water 2020, 12, 620. [CrossRef]

73. Massazza, G.; Tarchiani, V.; Andersson, J.C.M.; Ali, A.; Ibrahim, M.H.; Pezzoli, A.; De Filippis, T.; Rocchi, L.; Minoungou, B.; Gustafsson, D.; et al. Downscaling Regional Hydrological Forecast for Operational Use in Local Early Warning: HYPE Models in the Sirba River. Water 2020, 12, 3504. [CrossRef]

74. UNISDR Developing Early Warning Systems: A Checklist; UNISDR: Bonn, Germany, 2006. 